NBER WORKING PAPER SERIES

\title{
PAYMENTS CRISES AND CONSEQUENCES
}

\author{
Qian Chen \\ Christoffer Koch \\ Padma Sharma \\ Gary Richardson \\ Working Paper 27733 \\ http://www.nber.org/papers/w27733 \\ NATIONAL BUREAU OF ECONOMIC RESEARCH \\ 1050 Massachusetts Avenue \\ Cambridge, MA 02138
}

August 2020

For comments and suggestions, we thank seminar participants at the Federal Reserve Banks of Cleveland, Dallas, and Kansas City, and at the University of California at San Diego and at Irvine. Kaspar Wuthrich, Johannes Wieland, James Hamilton, Valerie Ramey, Titan Alon, Martin Stuermer, and Pavel Kapinos provided particularly helpful comments. The views expressed in this paper are those of the authors and do not necessarily reflect the views of the Federal Reserve Bank of Dallas, Federal Reserve, nor do they necessarily reflect the views of the National Bureau of Economic Research.

NBER working papers are circulated for discussion and comment purposes. They have not been peer-reviewed or been subject to the review by the NBER Board of Directors that accompanies official NBER publications.

(C) 2020 by Qian Chen, Christoffer Koch, Padma Sharma, and Gary Richardson. All rights reserved. Short sections of text, not to exceed two paragraphs, may be quoted without explicit permission provided that full credit, including (C) notice, is given to the source. 
Payments Crises and Consequences

Qian Chen, Christoffer Koch, Padma Sharma, and Gary Richardson

NBER Working Paper No. 27733

August 2020

JEL No. C01,C11,E02,E32,E44,E58,G01,G2,G21,G28

\begin{tabular}{|c|c|}
\hline \multicolumn{2}{|c|}{$\underline{\text { ABSTRACT }}$} \\
\hline \multicolumn{2}{|c|}{$\begin{array}{l}\text { Banking-system shutdowns during contractions scar economies. Four times in the last } \\
\text { governors suspended payments from state-insured depository institutions. Susp } \\
\text { payments in Nebraska (1983), Ohio (1985), and Maryland (1985), which were short ar } \\
\text { during expansions, had little measurable impact on macroeconomic aggregates. Rho } \\
\text { payments crisis (1991), which was prolonged and occurred during a recession, leng } \\
\text { deepened the downturn. Unemployment increased. Output declined, possibly p } \\
\text { relative to what might have been. We document these effects using a novel Bayesian } \\
\text { synthetic control that characterizes the principal types of uncertainty in this form of an } \\
\text { findings suggest policies that ensure banks continue to process payments during cor } \\
\text { including the bailouts of financial institutions in } 2008 \text { and the unprecedented sup } \\
\text { financial system during the COVID crisis - have substantial value. }\end{array}$} \\
\hline Qian Chen & Padma Sharma \\
\hline Beijing Technology and & Federal Reserve Bank of Kansas City \\
\hline Business University & 1 Memorial Drive \\
\hline 33 Fucheng Road Haidian District & Kansas City, MO \\
\hline Beijing 100048 & Padma.Sharma@kc.frb.org \\
\hline \multicolumn{2}{|l|}{ China } \\
\hline chenqiannku@163.com & Gary Richardson \\
\hline & Department of Economics \\
\hline Christoffer Koch & University of California, Irvine \\
\hline Federal Reserve Bank of Dallas & 3155 Social Sciences Plaza \\
\hline 2200 North Pearl Street & Irvine, CA $92697-5100$ \\
\hline Dallas, TX 75201 & and NBER \\
\hline Christoffer.Koch@dal.frb.org & garyr@uci.edu \\
\hline
\end{tabular}




\section{Introduction}

Policymakers strive to ensure commercial banks process payments on a business-as-usual basis at all times. An imperative for the Federal Reserve, Alan Greenspan writes, is "to ward off financial paralysis - a chaotic state in which businesses and banks stop making the payments they owe each other and the economy grinds to a halt (Greenspan, 2008, pp. 105-6)." "Banks are like the economy's circulatory system," Timothy Geithner writes, "as vital to its everyday functioning as the power grid (Geithner, 2014, p. 3)." Even modest disruptions of banks' payment operations "cause horrific pain (Geithner, 2014, p. 14)." During the financial crisis of 2007-2009, Ben Bernanke writes, the Fed's extraordinary actions were necessary to prevent a catastrophe like the contractions caused by widespread banking panics and payment suspensions during the nineteenth century and Great Depression (Bernanke, 2013). Similar concerns appear to underlie the Federal Reserve's extraordinary actions to support depository institutions during the current COVID-19 crisis.

The validity of policymakers' fears and the value of policies based upon them is difficult to determine. ${ }^{1}$ A venerable literature describes banking panics of the Gilded Age and Great Depression, which often deepened and occasionally triggered downturns (Sprague, 1910; Wicker, 2000; Chabot, 2011; Richardson and Sablik, 2015; Davison and Ramirez, 2014; Jalil, 2015; Gorton and Tallman, 2016). This literature, however, struggles to differentiate the consequences of payment and credit disruptions. Given the institutions at the time and the data extant today, credibly disentangling the two may be impossible, and given the evolution of economies over the last century, the relevance of those estimates to modern policy makers may be questioned. A theoretical literature exists in which scholars calibrate models and calculate benefits from reducing payment frictions Rocheteau and Wright (2005), Bethune, Rocheteau, and Rupert (2015), Guerrieri and Lorenzoni (2009), and Guerrieri and Lorenzoni (2017). These models indicate that suddenly preventing agents from making payments with a substantial share of their liquid assets could have a large negative impact on the economy. Direct empirical work on the impact of suspensions of payments on modern developed economies, however, is limited.

The limiting factor is lack of data. Since the Great Depression, policymakers for the worlds' leading economies have ensured that commercial banks processed payments in all states of the world, even during the worst crises, even shocks that forced equity markets to close, like the 9/11 terrorist attacks. To accomplish this feat, policymakers strengthened central banks and regulatory agencies and bailed out systemically-important commercial banks when they seemed on shaky ground. Are expenditures like this - particularly the bailouts -

\footnotetext{
${ }^{1}$ The public appears to share these concerns. The Federal Reserve (www.federalreservehistory.org) and Federal Deposit Insurance Corporation's (www.fdic.gov) web sites explain that their organizations exist to prevent recurrences of our nation's historical experience with commercial-banking crises and suspensions of payments.
} 
worthwhile? If policymakers had allowed a substantial share of commercial banks to suspend operations in 2008, after the failure of Lehman Brothers, what would have happened? A substantial share might be the same as in the Great Depression of the 1930s, when banks holding about $12 \%$ of all deposits involuntarily suspended operations between the stock-market crash of 1929 and the banking holiday in 1933. We know of no direct answer to this question.

Our essay fills this lacuna in the literature by examining a series of state-level shocks originally elucidated by William English (1993). These are the suspensions of payments in Nebraska in 1983, Ohio in 1985, Maryland in 1985, and Rhode Island in 1991. In each of these states, governors suspended payments from all financial institutions insured by a state-chartered deposit-insurance program when mismanagement or defalcation at an insured member resulted in losses that threatened the program's stability and triggered runs at healthy intermediaries. These suspensions varied in length, magnitude, and relationship to the business cycle. In the largest, Rhode Island and Maryland, the share of deposits trapped in suspended banks exceeded the share trapped in suspensions during the Great Depression. ${ }^{2}$ These are the only statewide suspensions of payments by depository institutions since the Federal Deposit Insurance Corporation began operations 85 years ago.

Our analysis asks whether these payment-systems shocks, which temporarily reduced the liquidity of households' and firms' portfolios, impacted macroeconomic aggregates, such as unemployment, labor force participation, and gross state product, and whether the impact depended upon the magnitude of the shock or its correlation with the business cycle. Our methods are shaped by the structure of this historical experiment. We examine data aggregated at the state level. We observe four suspensions, which we often refer to as treatments, to conform to the lexicon common in the literature. Each treatment affected a single state at a single point in time. The correct control group is unclear. Which states had experiences most similar to the treated state prior to treatment?

In these circumstances, the method of synthetic control provides a data-driven procedure to determine an appropriate baseline against which to compare the outcome for the treated state. A synthetic control is constructed from a convex combination of comparison units. This weighted average approximates the characteristics of the state exposed to the shock. A synthetic control provides a better comparison for the state exposed to the intervention than any single comparison state alone. This method facilitates causal inference when an-

\footnotetext{
${ }^{2}$ Rhode Island's experience, which is a focus of our analysis, probably influenced U.S. policymakers' expectations of what would have occurred in 2008 if the government had not taken extraordinary actions to protect the banking and payment system following Lehman Brothers' bankruptcy. Articles about Rhode Island's crisis and the simultaneous credit crunch in New England had been written by several members of the FOMC, including the Chair and the President of FRB Boston, and also by several senior Fed staffers (e.g. Bernanke and Lown, 1991; English, 1993; Pulkkinen and Rosengren, 1993). Other members of these groups experienced these events firsthand at a formative stage in their career, because they lived at the time in New England or worked on the Fed's teams responding to these events.
} 
alyzing comparative case studies with aggregate data (Abadie and Gardeazabal, 2003; Abadie, Diamond, and Hainmueller, 2010; Abadie, Diamond, and Hainmueller, 2015; Born, Müller, Schularick, and Sedláček, 2019; Born, Müller, Schularick, and Sedláček, 2020). Synthetic control allows us to clearly compare macroeconomic aggregates from states whose governors suspended payments of deposits to a comparable set of states whose governors who did not.

Inference in synthetic control is an active area of research (Li, 2019; Chernozhukov, Wuthrich, and Zhu, 2018; Chernozhukov, Wuthrich, and Zhu, 2019; Ben-Michael, Feller, and Rothstein, 2018; Ben-Michael, Feller, and Rothstein, 2019; Arkhangelsky, Athey, Hirshberg, Imbens, and Wager, 2019). We recast the standard synthetic control as a Bayesian estimation problem. We estimate distributions of weights for comparison units, which in turn, yield distributions for the synthetic control, average treatment effect, and cumulative treatment effect. These distributions elucidate the impact of the treatment and precision of the estimate. They also yield information about the probability of particularly bad (or good) outcomes.

Inference using our method has appealing intuition. The principal uncertainty underlying synthetic control is the composition of the control unit. We quantify this uncertainty and show how it can be magnified by post-treatment trajectories of untreated units. That insight enhances our understanding of the exercise. Our results for Rhode Island's banking crisis provide an example. The synthetic control is a weighted average of states whose economic aggregates resembled Rhode Island's before the crisis. Unemployment rates for that group continued to evolve in tandem after Rhode Island's banks shut down. Their similarity after the treatment date means little uncertainty exists about the synthetic control. ${ }^{3}$

The situation is different for gross state product (GSP). The GSPs of states whose economies resembled Rhode Island's in the decade before treatment (i.e. the 1980s) diverged in the decade after the crisis (i.e. the 1990s). GSP rose in all states, but it rose much more in states which benefited from the 1990s booms in information technology and financial services. In this case, varying weights across comparison states substantially changes our estimate of the average treatment effect. The more weight placed on states that grew more, the larger the estimate. The less weight placed on those states, the smaller the estimate. The post-treatment divergence of the untreated units results, in other words, is a wide and widening interval of uncertainty around the synthetic control. The tail of this diverging distribution contains very bad outcomes. Its width suggests payments crises could result in large declines of output relative to potential. In our example, this result arises for a clear reason. Rhode Island's payments crisis occurred at the start of a decade with booms in increasing-returns industries. The network and agglomeration externalities in these industries meant that they tended to concen-

\footnotetext{
${ }^{3}$ Consider, for example, a situation where the unit of interest has value $\mathrm{Z}$ before treatment and Z-A after treatment. The untreated comparison units have the constant value $Z$ before and after treatment. The synthetic control, which is a weighted average across the comparison units, will equal $\mathrm{Z}$ regardless of the weights. The treatment effect equals -A. There is no uncertainty.
} 
trate in a few places, like Silicon Valley in California, the Route 128 region in Massachusetts, and the New York metropolitan area. The finance and high-tech ships picked up steam in the early 1990s. Rhode Island missed those boats. It might have missed them because of its payments crisis, which occurred just as the internet became the "new new thing" and hi-tech firms chose cities in which to set up shop. That possibility is reflected in the wide probability interval for aggregate output, which indicates payments crises could result in large and prolonged reductions in output versus what might have been. ${ }^{4}$

Overall, we find that impact of suspensions of payments depends upon the phase of the business cycle. Suspensions of payments in Nebraska, Ohio, and Maryland - which occurred during economic expansions - had no systematic impact on economic aggregates. The crisis in Rhode Island - which occurred near the trough of a business cycle - had a substantial aggregate impact. Unemployment rose relative to the control group and remained elevated throughout the next business-cycle expansion. The unemployment rate converged to that of comparable states only during the next economic contraction, following the dot-com crash in 2001. The convergence occurred during that contraction because substantial numbers of men and women left Rhode Island's labor force, either because they ceased seeking work for a substantial period, or retired, or left the state. Relative to control states, many of Rhode Island's macroeconomic aggregates declined permanently. The decline in employment, for example, peaks a decade after treatment and remains substantial until our analysis ends in 2001.

The share of deposits trapped in Rhode Island's banks exceeded the share of deposits trapped in suspended banks throughout the United States during the Great Depression (Richardson, 2007). So, we use distributions derived from Rhode Island's experience from 1991 through 2006 to ask the question: what might have happened if U.S. policymakers had not bailed out the banking system following the collapse of Lehman Brothers in 2008, a counterfactual which policymakers asserted might have led to a financial catastrophe like the 1930s. This exercise helps to address our broader question: do the costs of keeping deposits liquid in all states of the world justify the benefits?

\section{Historical Background}

This section discusses issues important for understanding our analysis and conclusions. One is why governments expend resources to ensure that payment intermediaries, particularly

\footnotetext{
${ }^{4}$ Consider a case where the unit of interest has value $\mathrm{Z}$ before treatment and Z-A after treatment. Before treatment all of the comparison units have the constant value $Z$. After treatment, half of the comparison states retain the value $Z$ and half change to value $10^{*} Z$. As weights vary across the untreated units, the synthetic control varies from $Z$ to $10 Z$, and the treatment effect ranges from -A to $-A-9 Z$.
} 
commercial banks, operate routinely regardless of the state of the economy. Two is how much governments expend on this task. Three is why governors of four states suspended payments from depository institutions between 1983 and 1991 and how these suspensions impacted firms' and households' balance sheets. This information elucidates the importance of the issues that we examine and indicates that the methods we use yield accurate conclusions.

\subsection{Why Societies Fear Suspensions of Payments}

Fear of payments crises stems from historical experience and modern understanding of the importance of payment systems. Most payments for goods and services begin, end, and often also transit through deposit accounts at financial institutions. Today, these transfers are typically electronic. ${ }^{5}$ From the 1880 s through the 1980s, the preponderance of payments by value were checks. Most checking deposits were held at commercial banks, and most check processing was done by commercial and central banks.

Banks typically make payments when depositors' ask them to do so, but the law does not require banks to make payment at that time. The pace of payments is at banks' and regulators' discretion. Contracts and laws allow banks and regulators to delay payments for short periods at will and for longer periods with cause. At their own discretion, for example, banks can require depositors to provide thirty days notice prior to withdrawing savings deposits. Banks can refuse to redeem certificates of deposit until maturity. Banks can also delay payment on demand deposits (i.e. checking accounts) for several days (five was common, although the number varies across jurisdictions and over time). Banks can delay paying checks for longer periods during emergencies if they promise to pay in full when the emergency passes and demonstrate to regulators that they have the ability to do so. Regulators can order individual banks or the banking system as a whole to postpone payments if they believe it is in the interest of an institution's depositors or the general public. These rules protect banks from sudden drains of deposits, like bank runs, that could trigger fire sales and

\footnotetext{
${ }^{5}$ In the U.S. in 2015, for example, 72 percent of all payments by value were transfers of this type with 19 percent by check, 18 percent by debit, and 35 percent by other electronic transfer methods, such as payments via $\mathrm{ACH}$. Credit amounted to $16 \%$ of all payments by value. Only 9 percent of payments by value were made with cash. In the 1980s, transfers on the books of financial institutions amounted to similar fraction of all payments by value, although a much smaller share were electronic, and a much larger share were check. When a customer pays for groceries with a debit card, their swipe at a cash register transfers funds from their bank account to their grocer's. While households use currency and coin for small payments and credit cards for other purchases, the ultimate source and destination for almost all of these transfers are individuals' and firms' accounts at depository institutions. Households typically obtain cash by withdrawing funds from their deposit accounts (often via automated teller machines). Firms that receive cash payments typically deposit those funds in their accounts shortly after receipt. For additional information on this topic, see the Federal Reserve Payments Study at https:/ / www.federalreserve.gov / paymentsystems/fr-payments-study.htm, the Diary of Consumer Payment Choice at https://www.frbatlanta.org/banking-and-payments/consumer-payments/diary-of-consumerpayment-choice?panel=1, and the Survey of Consumer Payment Choice at https:/ / www.frbatlanta.org/bankingand-payments/consumer-payments/survey-of-consumer-payment-choice/2019-survey?panel=1
} 
destabilize an individual bank or the entire the financial system. These rules, however, mean that payment flows through the banking system can suddenly freeze. These freezes have been traditionally called suspensions of payments, or in modern times, payments crises.

Suspensions of payments occurred intermittently in the past, usually but not always during recessions, when banks ceased paying checks or honoring requests to withdraw cash over their counters. Widespread suspensions of payments occurred in 1837, 1857, 1873, 1884, 1893, 1901, 1907, 1929, and repeatedly between 1930 to 1933 (Wicker, 2000; Richardson, 2007; Richardson and Troost, 2009; Carlson, Mitchener, and Richardson, 2011; Davison and Ramirez, 2014; Jalil, 2015). Smaller, local suspensions occurred sporadically between these dates (Davison and Ramirez, 2014; Jalil, 2015). The larger episodes deepened or triggered economic downturns (Sprague, 1910; Cohen, Hachem, and Richardson., 2020).

Congress tried to solve the problem of suspension on several occasions. In 1863, Congress passed the National Banking Act, to create a network of nationally supervised institutions with safer assets, more liquidity, and less susceptibility to suspension than the statechartered institutions that existed before. In 1913, Congress established the Federal Reserve System, to stabilize interest rates, prevent panics, and prevents shutdowns of the banking system like the Panic of 1907. The collapse of the banking system during the contraction of the 1930s, however, demonstrated the reforms had not solved the problem. During the New Deal, the federal government responded by establishing a nationwide deposit insurance system. The Federal Deposit Insurance Corporation (FDIC, established 1933) insured deposits of all nationally-chartered commercial banks and any state-chartered commercial bank that voluntarily joined the organization. The Federal Savings and Loan Insurance Corporation (FSLIC, established 1934, dissolved 1989) insured deposits at all nationally-chartered savings and loans (S\&Ls) and any state-chartered thrifts (i.e. S\&Ls and similar state-chartered institutions) that voluntarily joined the organization. The federal government also tightened regulations regarding the operation of commercial banks, restructured the banking industry, and increased resources devoted to the supervision of banks (Komai and Richardson, 2011).

In addition to historical experience, economic theory suggests the payment system has important functions. Increasing payment frictions (such as suspending payments on deposit accounts) can reduce output, employment, and firm entry, while increasing unemployment and bankruptcies. These models stem from the foundation of Lagos and Wright (2005) and Mortensen and Pissarides (1994). Recent models in this literature include firm entry and exit, unemployment, payments, and credit. Examples include Rocheteau and Wright (2005), Bethune, Rocheteau, and Rupert (2015), Guerrieri and Lorenzoni (2009), Guerrieri and Lorenzoni (2017), Wasmer and Weil (2004), Beaudry, Galizia, and Portier (2017), and Beaudry, Galizia, and Portier (2020). In these models, some households have access to credit. Others pay for products with liquid assets (i.e. money or deposits) that they accumulate. Credit lim- 
its are endogenous, and credit frictions impact the level and persistence of unemployment. Multiple equilibria exist, and changes in the supply of money and credit generate volatility and co-movements across producers. An exogenous reduction in households' cash holdings will lead to an economic contraction. The impact of the shock may depend upon the state of the economy. During booms, when credit limits are high and more households have access to credit, shocks to households' cash holdings or increasing frictions in the cash payment system, should have a smaller impact than similar shocks during recessions, when credit is constrained and firms and households may respond more substantially to payment shocks and bad news.

\subsection{Governments Spend Substantial Resources to Prevent Payments' Crises}

Financial regulation is costly, and its benefits are nebulous. Uncertainty about both spans several orders of magnitude (Cochrane, 2014). The direct costs of financial regulation are large at the federal level. In 2019, the FDIC's expenditures totaled $\$ 1.8$ billion, the OCC amounted to $\$ 1.3$ billion, and the Federal Reserve System's totaled $\$ 5.2$ billion. Employment at the FDIC exceeded 5,600, at the OCC exceeded 3,900, and at the Federal Reserve exceeded 22,800 . The indirect costs of bank regulation may be much larger. Scholars estimate the Dodd-Frank Act alone imposed on banks $\$ 50$ billion in paperwork and $\$ 108$ billion in legal fees (Batkins and Brannon, 2013). Scholars provide a wide range of estimates for the cost of regulating bank capital. Some estimate the impact on interest rates and lending to be "modest" (Kashyap, Stein, and Hanson, 2010; Kisin and Manela, 2016). Others conclude it is substantial (Garcia, 2019). The true costs of financial regulation may be of orders of magnitude larger, because financial regulations impact innovation, competition, allocations of credit, and the functioning of our economic and political systems, but the "important costs and benefits are nearly impossible to objectively quantify" (Cochrane, 2014).

When financial regulation fails and financial crises occur, modern governments typically bail out their banking systems. Examples in the U.S. include interventions to preserve Continental-Illinois in the 1980s, open-bank assistance provided to struggling banks and thrifts by the FDIC and FSLIC in the 1980s, and the bailout of commercial-bank counterparties of AIG following the failure of Lehman Brothers in 2008. Scholars provide a wide range of estimates for the cost of the latter. The lower bound is zero, because U.S. taxpayers eventually profited from their governments' actions. The upper bound is trillions of dollars (or more than the total value added to GDP by the financial sector from 1998 through 2008), which was the governments total outlay to purchase troubled assets and backstop struggling institutions from 2008 to 2012. Recent estimates place the total direct cost of crisis related bailouts in the United

States at nearly $\$ 500$ billion or 3.5\% of GDP in 2009 (Lucas, 2019). This figure is the value that U.S. financial institutions would have paid ex-ante for the transfers of resources that they 
received during the crisis.

The 3.5\% figure represents a transfer of wealth. It does not indicate real expenditures, such as resources consumed during and personnel working on bailout programs rather than producing goods and services for consumers. It also does not indicate production that would have been foregone if the banking system had not been bailed out, which might have lowered aggregate demand, by altering consumers' willingness and ability to purchase products, or aggregate supply, by raising costs of production or limiting firms' ability to hire workers or purchase inputs. A counterfactual estimate of this kind is what our paper provides.

\subsection{Why Governors Suspended Payments During the 1980s and 1990s}

Between 1956 and 1981, twenty-nine states established systems insuring deposits at statechartered banks, thrifts, and/or credit unions (English, 1993; Todd, 1994). ${ }^{6}$ Rising inflation made insuring deposits at the state level profitable, because state-insured institutions were unconstrained by federal regulations imposing maximum rates of interest on deposits and loans, which were imposed on all federally insured institutions (McKelvey, 1978). Most of these state insurance systems operated without incident, but between 1983 and 1991, four failed: Nebraska in 1983, Ohio and Maryland in 1985, and Rhode Island in $1991 .{ }^{7}$

These failures had common features (English, 1993; Calomiris, 1993; Todd, 1994). All occurred suddenly. The failed systems collected premia too low to cover the failure of multiple large institutions. Regulation of insured institutions was lax. Regulators had limited powers, collected insufficient information, and lacked the ability and incentive to preempt or punish fraudulent activity. Lax regulation allowed state-chartered financial institutions to take large risks, to be taken advantage of by financiers with more experience, and in some cases, to transfer funds to their friends or themselves. The situation was exacerbated by the deregulatory ethos of the time. Deregulation allowed financial institutions to enter lines of business which had potentially higher profits but also increased risks and in which they had little experience. Deregulation may have encouraged growing connections between bankers and politicians and induced regulators to look the other way when problems arose in hopes that market forces would correct the situation. In each of the four states, mismanagement or defalcation at a large insured institution resulted in losses that threatened the insurance fund's stability. The revela-

\footnotetext{
${ }^{6}$ States had established and discontinued such systems in the past, when economic conditions warranted. Since the early nineteenth century, state governments have chartered and regulated banks. States have also established deposit insurance systems. One group of insurance schemes operated before the Civil War. Another group operated in the early twentieth century. The insurance systems established in these waves of regulation eventually ceased operations. Given that history, the rapid spread of state-level insurance systems should not be surprising.

${ }^{7}$ Note that Mississippi's deposit insurance system failed in 1976. We do not analyze this incident because most of the data series that we analyze do not span that period.
} 
tion of the problem surprised regulators and the public. Unexpected bad news triggered runs at healthy members of the state insurance fund. Fears that the crisis would spread and that taxpayers would foot the bill to clean up the mess induced governors to suspend payments from all state-insured institutions until the situation could be sorted out (additional details of these events appear in Appendix B).

The suspensions varied in magnitude, length, and relationship to the business cycle. Details appear in Table 1. The suspensions in Rhode Island and Maryland involved substantial shares of deposits in those states. In Rhode Island, over 18\% of all deposits in the state (including federally insured) were initially held in suspended institutions. These institutions held accounts for more than a third of all state residents. This percentage exceeded the fraction of commercial bank deposits trapped in suspended banks during the Great Depression (12.6\%) with the exception of the banking holiday in the week of March 6, 1933. The trapped funds were a sizeable share of households' liquid wealth. Deposits in suspended institutions per household approached $14 \%$ of median annual household income. In Maryland, deposits in suspended institutions per household exceeded 19\% of median annual household income. The suspensions in Nebraska and Ohio involved a smaller share.

The first three crises occurred during expansions and were resolved quickly. ${ }^{8}$ The suspension of payments by institutions insured by the Rhode Island Share and Deposit Indemnity Corporation (RISDIC) occurred near the trough of a contraction. The pace of reopening was slow. On January 1, 1991, Rhode Island's governor froze all accounts in all 45 RISDIC insured institutions. Initially, depositors had no access to funds at closed institutions. At the end of the week, institutions holding 19\% of RSDIC-insured deposits reopened with federal insurance. From then until April, the remaining funds (including deposits from nearly $20 \%$ of the state's residents) remained frozen (House of Representatives, 1991a; House of Representatives, 1991b). In May 1991, partial payouts from RSDIC's successor DEPCO (which was set up to

\footnotetext{
${ }^{8}$ In Nebraska, three insolvent institutions shut their doors to depositors, but elsewhere, demand deposits remained accessible. Time and share deposits lost liquidity, because they could not be withdrawn early, but retained full value and could be withdrawn in full upon maturity. In Ohio, several insolvent institutions shut their doors permanently and most state-chartered S\&Ls closed their doors for two weeks. After that, depositors could withdraw $\$ 750$ per month from each account in each institutions that remained closed. This generous limit meant most families were not forced to cut consumption. Most closed institutions reopened fully within a month after attaining federal insurance. The FSLIC accelerated this process by rushing hundreds of examiners to the state (many borrowed from the Federal Reserve and other regulatory agencies) to quickly audit institutions, determine which qualified for FSLIC insurance, and expedite reopening. In Maryland, the state government acted to prevent bank runs by slowing withdrawals from state-insured institutions, but never suspended operations of solvent thrifts. The state imposed a withdrawal limit of $\$ 1,000$ per month per account until institutions qualified for federal insurance.Federal agencies expedited the transition to federal insurance by assigning additional employees to the task. The withdrawal cap approached $25 \%$ of the average household deposit and $5 \%$ of median household income. It also included exceptions for prescheduled payments (e.g. school tuition), debt payments (e.g. mortgages, car loans, and credit card bills), and obligations to governments (e.g. taxes). The withdrawal limit also included exceptions for businesses paying expenses, such as invoices and payroll. So, the payment crisis forced few families and firms to cut expenditures.
} 
clean up the mess) amounted to 7\% of trapped deposits. In June 1991, DEPCO paid another $23 \%$ of trapped deposits. The next substantial payouts occurred nearly a year later, in May 1992, when federally insured institutions acquired and reopened institutions holding $20 \%$ of trapped deposits, and in June 1992, when DEPCO paid off another $26 \%$ of trapped deposits. The remainder $(\approx 5 \%$ of the original frozen amount) were repaid in the next year (Pulkkinen and Rosengren, 1993; Todd, 1994).

Payoffs were delayed in Rhode Island principally for political reasons. Rhode Island could have paid and eventually did pay depositors in full. The crisis began during an election. Democrats ousted Republicans. The new Democratic governor shut down the financial system on his first day in office. Democrats blamed Republicans for the mess and used the debacle to advance their pre-crisis political program. Democrats cancelled a small cut in the state sales tax, which Republicans had passed the previous summer over Democratic opposition, asserting that the state needed the funds to cover RISDIC losses and to maintain the social safety net. Rhode Island's governor repeatedly lobbied the federal government for funds to repay depositors in full and appears to have delayed resolution to bolster its case that citizens would suffer unless the federal government covered the tab, which the state asserted would run roughly from $\$ 100$ million to $\$ 400$ million (or $\$ 100$ to $\$ 400$ per resident of the state). Congress repeatedly rebuffed Rhode Island's requests. Rhode Island also pursued legal restitution. It sued executives at failed financial institutions and the firm that audited RISDIC's accounts. The state recovered few funds from the executives but the auditing firm, Ernst \& Young, settled the suit for $\$ 103$ million. We have not been able to determine the eventual cost born by the state, which some documents indicate was near $\$ 100$ million, but given the rise in real estate prices in Rhode Island from 1995 to 2005, a strategy must have existed for the state to resolve the situation without loss.

While depositors' funds remained trapped in Rhode Island for a prolonged period, other aspects of the banking and payment systems remained in operation. Electronic payment networks such as credit card processors remained operated without interruption. The Federal Reserve Bank of Boston ensured sufficient cash remained available in all communities. The Reserve Bank expedited loans and rushed cashed to member banks in Rhode Island and southeastern Massachusetts. It also acted to ensure that local nodes in automated teller networks remained in operation. FRB Boston's payment's experts rerouted all Automated Clearing House (ACH) payments - including Social Security checks and similar federal and state payments - heading towards accounts at closed institutions to alternative accounts at federally-insured institutions in nearby communities that remained in operation.

Differences among these crises should not overshadow common characteristics (English, 1993; Todd, 1994). All of the suspensions were sudden and unanticipated. The preponderance of depositors did not known their funds were at risk or that they were ensured by state- 
chartered entities, rather than a national program backed by the full faith and credit of the federal government (Congress:1991). Depositors did not prepare for the suspensions before they occurred. None of the crises spread to neighboring states or triggered suspensions of depositories which were federally-insured. Spillovers were limited because regulators strove to limit contagion, and in the case of Rhode Island, because it was small relative to neighboring states. These common characteristics suit these events for synthetic-control analysis.

\section{A First Look at the Data}

Key targets for central banks include inflation, employment, and output. Measures of employment, unemployment, labor-force participation, and gross domestic product (but neither inflation nor prices) exist for U.S. states from the 1970s until today. These series' lengths and consistent measurement suit them for synthetic-control methods, which require extended runs of pre-treatment data to determine appropriate weights for comparison units.

We initially examine these series using standard methods of synthetic control for the crisis in Rhode Island and then for the other states. We construct a synthetic control for unemployment in Rhode Island using the method of (Abadie and Gardeazabal, 2003). This method determines the weighted average of monthly unemployment rates for the other 49 states that best fits Rhode Island's experience prior to the RISDIC crisis in January 1991 (see Section 4 for estimation details). This convex combination is $64.1 \%$ Massachusetts, $20.2 \%$ Delaware, $13.6 \%$ Michigan, and $2.1 \%$ New Hampshire. This group seems reasonable. Massachusetts borders Rhode Island. New Hampshire is the next state to the north. Their occupational structures resemble Rhode Island's. So does Delaware's. Like Rhode Island, Massachusetts, New Hampshire, and Delaware experienced credit-fueled expansions in the early 1980s and experienced a sharp contraction at the end of the decade. The control group excludes Rhode Island's western neighbor, Connecticut, whose employment patterns in the 1980s moved with its neighbor New York.

The comparison of unemployment rates between Rhode Island and the synthetic control appears in Figure 1a. The vertical line marks the month of Rhode Island's crisis, January 1991. Before that date, the unemployment rate in Rhode Island moved in lockstep with the control. Unemployment fell steadily from 1985 through 1988, but then rose rapidly in 1989 and 1990. Rhode Island's crisis occurs near the trough of the contraction. Three months later, when unemployment peaked in the control and began to decline, unemployment in Rhode Island continued to rise, peaking after another year and a half. By 1993, unemployment was declining in both Rhode Island and the controls. Recovery in the two groups progressed at same rate. This parallel path meant that unemployment in Rhode Island remained elevated relative to the controls until the next recession in 2001. After that recession, Rhode Island's unemployment 
rate converged with unemployment in its control.

The magnitude of the impact on unemployment was sizeable. During the six years after the shock in Rhode Island, unemployment averaged 0.86 percentage points higher each month than in states with comparable patterns of unemployment before treatment. This steady difference meant that over these 72 months, the working men and women of Rhode Island suffered 245,749 months of unemployment more than they would have if their state's unemployment rate evolved like rates of comparable states that did not suspend payments. If these losses had been imposed equally across the labor force, each worker would have lost approximately two-and-a-half weeks of work or just over five percent of a year's income.

The remaining panels of Figure 1 compare Rhode Island's experience to synthetic controls for three additional macroeconomic aggregates. Figure $1 \mathrm{~b}$ examines labor force participation. The participation rate declined over 3 percentage points in Rhode Island relative to controls. The decline occurred gradually. The impact peaked nearly 4 years after the RISDIC crisis. Recovery was also gradual. The labor force participation remained 1 percentage point below controls for more than a decade. Figure 1c examines employment. The level of employment declines steadily and substantially relative to controls. The number of lost jobs approaches 40,000 four years after the crisis. This decline appears to have been prolonged and possibly permanent. These losses reflect additional unemployment, reduced labor force participation, and a declining population. Figure 1d shows that aggregate output also declined substantially in Rhode Island relative to controls.

Figure 2 compares Rhode Island's post-RISDIC crisis to the post-suspension crises in Maryland, Nebraska, and Ohio. In Figure 2a, each line indicates the unemployment rate in a treated state minus its synthetic control. For Rhode Island, this is the vertical distance between the two curves in Figure 2a. In Rhode Island, unemployment rose rapidly relative to control and remained elevated for nearly 10 years. In Nebraska, unemployment fell relative to controls. This decline continued, with gyrations, for ten years. In Ohio, unemployment initially rose relative to synthetic control. The increase was temporary and small. A few years after onset, Ohio's unemployment was lower than the control and remained below for the rest of the decade. In Maryland, the unemployment rate initially fell relative to controls and fluctuated after that.

The remaining panels examine additional macroeconomic aggregates. After the payments crises in Maryland, Ohio, and Nebraska, Figure 2b shows that labor force participation changed little or rose slightly. Figure $2 c$ shows that employment rose substantially in Ohio and slightly in Nebraska and Maryland. In the latter, employment eventually declined. This decline, however, coincided with declines in Federal government expenditures after the Republicans took control of Congress at the end of 1992, which impacted Maryland substantially, because the federal government was one of the state's largest employers. Figure $2 \mathrm{~d}$ shows 
gross state product initially rose in Ohio and Maryland and eventually fluctuated in all states except Rhode Island, where it steadily declined.

Our initial examination of the evidence illuminates clear patterns. The RISDIC crisis in Rhode Island preceded adverse movements in macroeconomic aggregates. The crises in other states did not.

\section{Synthetic Control and Bayesian Inference}

The causal impact of an event is the difference between reality, the outcome that occurred, and counterfactual, the outcome that would have occurred in the absence of the treatment. The counterfactual is unobserved but estimable. Our previous section estimates counterfactual values using the synthetic control method developed by Abadie and Gardeazabal (2003). The method of Abadie and Gardeazabal constructs a control from a convex combination of untreated units that best approximates the characteristics of the treated unit in the pre-treatment period. The method was developed to estimate treatment effects resulting from interventions that were enacted at an aggregate level, such as states or counties, rather than for individuals or firms who might have been randomly selected or chosen by criteria. Synthetic control methods are suited to settings where there are a small number of treated units, a larger number of untreated units, and where no single untreated unit serves as a suitable control. These characteristics clearly resemble our scenario, with four states out of fifty receiving treatments at different dates during a decade.

For the classic synthetic control, we consider $Y_{1}$, a $T \times 1$ vector of the outcome of interest such as unemployment from the treated unit, say, Rhode Island, observed over $T$ periods and $\mathbf{Y}_{0}$, a $T \times J$ matrix of outcomes pertaining to $J$ untreated units, which in our case constitute the remaining 49 U.S. states and DC. We denote the intervention period by $T_{0}$ and introduce $Y_{j t}^{N}$ and $Y_{j t}^{I}$ to represent the potential outcome for unit $j$ without and with intervention respectively over the post-treatment period $t=T_{0}+1, \ldots, T$. Accordingly, we observe $Y_{1\left[T_{0}+1: T\right]}^{I}$

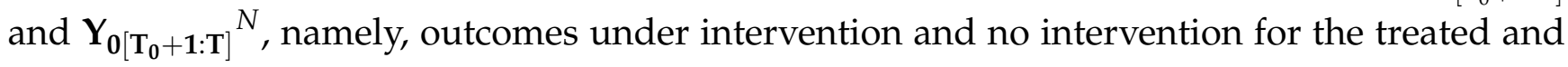
untreated units respectively. The objective of this exercise is to estimate counterfactual outcomes $\hat{Y}_{1\left[T_{0}+1: T\right]}^{N}$ for the treated unit, which in the illustrative case depicts economic outcomes for Rhode Island had there been no suspension of payments in January 1991. In the following discussion, time subscripts are suppressed except when they are required to be explicitly stated.

The counterfactual $\hat{Y}_{1}^{N}$ is constructed by assigning weights $W^{\star}=\left(w_{1}^{\star}, w_{2}^{\star}, \ldots, w_{J}^{\star}\right)$ to each of the $J$ untreated units to obtain $\hat{Y}_{1}^{N}=\mathrm{Y}_{0} W^{\star}$. The difference between $Y_{1}$ and $\hat{Y}_{1}^{N}$ over the course of the post-treatment period is an estimate of the treatment effect. The optimal 
weights $W^{\star}$ are obtained by minimizing the following squared loss function,

$$
\min _{w \in W}\left(X_{1\left[1: T_{0}\right]}-\mathbf{X}_{\mathbf{0}\left[\mathbf{1}: \mathbf{T}_{\mathbf{0}}\right]} W\right)^{\prime} V\left(X_{1\left[1: T_{0}\right]}-\mathbf{X}_{\mathbf{0}\left[\mathbf{1}: \mathbf{T}_{\mathbf{0}}\right]} W\right)
$$

subject to $w_{1}+w_{2}+\ldots+w_{J}=1, w_{j} \geq 0$ for all $j=1,2, \ldots, J . X_{1}$ is a set of $K \times 1$ predictors for outcome $Y_{1}$ averaged over the pre-treatment period and $\mathbf{X}_{\mathbf{0}}$ is a $K \times J$ matrix of the same $K$ averaged predictors based on the $J$ untreated units. The matrix $V$ assigns weights to each of the $K$ predictors and determines their relative importance in the prediction of the outcome of interest. We follow the recommendation of Abadie and Gardeazabal (2003) and use their algorithm to select an optimal $V^{\star}$ by minimizing the squared differences between treated and synthetic control outcomes in the pre-treatment period, i.e.,

$$
V^{\star}=\min _{v \in V}\left(Y_{1\left[1: T_{0}\right]}-\mathbf{Y}_{\mathbf{0}\left[\mathbf{1 : \mathbf { T } _ { \mathbf { 0 } } ]}\right.} W(V)\right)^{\prime} V\left(Y_{1\left[1: T_{0}\right]}-\mathbf{Y}_{\mathbf{0}\left[\mathbf{1}: \mathbf{T}_{\mathbf{0}}\right]} W(V)\right)
$$

We extend the standard synthetic control using a Bayesian method which we introduce in this essay. Inference in synthetic control is an active area of research. A Bayesian approach has advantages. It facilitates inference in finite sample settings on all objects of interest including weights for control units, the treatment effect at any point in time, and transformations of the treatment effect such as the average or cumulative. It works, in other words, for small samples. It directly addresses the key uncertainty in synthetic control methods, the appropriate sample weights. It provides the distribution of the treatment effect and mathematical transformations of that distribution. It also yields insights into the sources of uncertainty when conducting counterfactual analysis that may not be as apparent when using other methods. We elaborate on this issue below. Finally, it provides information useful to policymakers. An example is a probability distribution around the average treatment effect which can tell you the probability of and the reason for a very large effect, which is the type of tail event that policymakers must plan for. ${ }^{9}$

Bayesian estimation and inference requires the specification of a likelihood-based data generating process for the outcome, $Y_{1}$, and prior distributions for the parameters in the likelihood. We model the outcome for the treated sample $Y_{1}$ as being centered around the convex combination of untreated units, $\mathbf{Y}_{0} W$, with Gaussian errors characterized by variance $\sigma^{2}$,

$$
Y_{1}=\mathbf{Y}_{0} W+\epsilon, \quad \text { where } \quad \epsilon \sim \mathbb{N}\left(\mathbf{0}, \sigma^{2} \mathbb{I}_{T}\right)
$$

The Bayesian counterpart of the synthetic control estimate arises from minimizing the posterior expectation of the quadratic loss function $\mathcal{L}$ under the constraints $\sum_{j=1}^{K} w_{j}=1$ and $w_{j} \geq 0$,

\footnotetext{
${ }^{9}$ Note: The method used in this essay could be modified to better estimate the tails of the treatment distribution or quantile treatment effects by using a different loss function.
} 
where,

$$
\mathcal{L}=\int\left(Y_{1}-\mathbf{Y}_{0} W\right)^{\prime}\left(Y_{1}-\mathbf{Y}_{0} W\right) f\left(W, \sigma^{2} \mid Y_{1}\right) d W d \sigma^{2}
$$

The posterior mean of $W$ and $\sigma^{2}$ represent the Bayes estimate as the loss function being minimized is quadratic (Poirier, 1995). The posterior mean is computed from $G$ draws from the posterior distribution of $W$ and $\sigma^{2}$. We develop a Markov Chain Monte Carlo (MCMC) algorithm to generate the draws from the posterior distribution. Since the enforcement of the non-negativity and sum-to-one constraints on weights can result in computational complexities in sampling from the posterior, we introduce unconstrained parameters $\psi$ that are transformations of the vector of weights $W$ and are therefore computationally less burdensome to estimate than the latter, where,

$$
w_{j}=\frac{e^{\psi_{j}}}{\sum_{\ell=1}^{K} e^{\psi_{\ell}}} .
$$

We specify multivariate Gaussian priors $f_{N}\left(\psi_{0}, S_{0}\right)$ for the vector of parameters $\psi$ and a Gamma prior, $f_{G}(\vartheta, d)$ for the error variance $\sigma^{2}$. The rationale for the prior distribution of the transformed parameter $\psi$ arises from literature on distributional specifications for compositional data in a simplex such as the weights in our study. Aitchison (1982) noted the shortcomings of the Dirichlet distribution in describing the variability of compositions and recommended transformed normal distributions as suitable alternatives.

Following the specification of the likelihood and priors, the posterior density of $\left\{\psi, \sigma^{2}\right\}$ can now be represented as follows,

$$
f\left(\psi, \sigma^{2} \mid Y_{1}\right) \propto f\left(Y_{1} \mid \psi, \sigma^{2}\right) f_{\mathcal{N}}\left(\psi \mid \psi_{0}, S_{0}\right) f_{\mathcal{G}}\left(\sigma^{2} \mid \vartheta, d\right)
$$

In designing an MCMC sampler to sample from the above posterior, we are precluded from constructing a Gibbs sampler that iteratively samples from the conditional distributions of the parameters as the latter do not belong to well-known parametric families. We therefore use a Metropolis-Hastings algorithm with an independence proposal and estimate the parameter vector $\theta=\left\{\psi, \sigma^{2}\right\}$ in one block. We use the proposal density $q\left(\theta \mid Y_{1}\right) \sim f_{T_{\omega}}(\theta \mid \widehat{\theta}, a H)$, a multivariate T distribution with $\omega$ degrees of freedom where $\widehat{\theta}=\widehat{\theta}_{M L E}, H$ is an identity matrix and $a$ is a tuning parameter.

The estimation algorithm is summarized follows.

1. Start with current draw $\theta^{c}$ from the prior $f(\theta)$

2. Draw the proposed value $\theta^{p}$ from the proposal density $q\left(\theta \mid Y_{1}\right)=f_{\mathcal{T}_{\omega}}(\theta \mid \hat{\theta}, a H)$ 
3. Accept $\theta^{p}$ with probability $\alpha_{M H}\left(\theta, \theta^{p}\right)$,

$$
\alpha_{M H}\left(\theta, \theta^{p}\right)=\min \left\{1, \frac{f\left(Y_{1} \mid \theta^{p}\right) f\left(\theta^{p}\right) q\left(\theta^{c} \mid Y_{1}\right)}{f\left(Y_{1} \mid \theta^{c}\right) f\left(\theta^{c}\right) q\left(\theta^{p} \mid Y_{1}\right)}\right\}
$$

otherwise repeat the current value $\theta^{c}$.

In implementing this algorithm we specify prior hyperparameters so that the mean of each element of $\psi$ is 0 with a standard deviation of 5 . Similarly, we specify non-informative priors for $\sigma^{2}$ with a mean of 90 and a standard deviation of 22. The vector of tuning parameter $a$ consists of values 0.1 corresponding to the variances of $\psi$ and 0.01 corresponding to the variances of $\sigma^{2}$.

On generating $\mathrm{G}$ draws from the posterior density of $\psi$ and $\sigma^{2}$, we recover the posterior draws of weights $W$ from the marginal posterior density $f\left(W \mid Y_{1}\right)$ using the transformation in Equation (3). Subsequently, we evaluate the vector of synthetic control outcomes, $\hat{Y}_{1}^{N, b}=$ $\mathrm{Y}_{0} W^{b \star}$ where $W^{b \star}$ is the Bayes estimate of the weights, namely the posterior mean resulting from the $G$ samples. The posterior draws of the weights $W^{(g)}$ also generate a full posterior sample of $G$ draws of the synthetic control outcome, $\hat{Y}_{1}^{N,(g)}=\mathbf{Y}_{0} W^{(g)}, g=1,2, \ldots, G$, at each time period $t=1,2, \ldots, T$. This posterior sample allows inference on the treatment effects, $Y_{1, t}-\hat{Y}_{1, t}^{N}$ at each $t$ within the post-treatment period.

A straightforward evaluation of the distribution of the average treatment effect (ATE) is as follows,

$$
\operatorname{ATE}^{(g)}=\frac{1}{T-T_{0}} \sum_{t=T_{0}+1}^{T}\left(Y_{1, t}-\hat{Y}_{1, t}^{N,(g)}\right), g=1,2, \ldots, G
$$

The mean ATE is obtained by averaging across all draws from the posterior of $W$, i.e.,

$$
\begin{aligned}
\text { Mean ATE } & =\int \frac{1}{T-T_{0}} \sum_{t=T_{0}+1}^{T}\left(Y_{1, t}-\hat{Y}_{1, t}^{N} \mid \theta\right) f\left(\theta \mid Y_{1}\right) d \theta \\
& \approx \frac{1}{G\left(T-T_{0}\right)} \sum_{g=1}^{G} \sum_{t=T_{0}+1}^{T}\left(Y_{1, t}-\hat{Y}_{1, t}^{N,(g)}\right) .
\end{aligned}
$$

We can flexibly extend measurements of treatment effects to incorporate cumulative treatment effects by evaluating cumulative sums of the treatment effect until each period $t^{\prime}$ in the posttreatment period, $t^{\prime} \in\left\{T_{0}+1, \ldots, T\right\}$. Inference on this quantity of interest is not possible in classical methods.

A key inferential quantity of interest that sheds light on the statistical importance of the treatment effect is the probability of the outcome from the synthetic control sample taking values above or below the treated outcome. The Bayesian framework provides a straightforward 
way to evaluate this quantity. The posterior probability of interest is,

$$
\operatorname{Pr}\left(\hat{Y}_{1, t}^{N}<Y_{1, t} \mid Y_{1}\right)=\int_{-\infty}^{Y_{1, t}} f\left(\hat{Y}_{1, t}^{N} \mid Y_{1}\right) d \hat{Y}_{1, t}^{N}
$$

This probability can be evaluated by using the posterior samples as follows,

$$
\operatorname{Pr}\left(\hat{Y}_{1, t}^{N}<Y_{1, t} \mid Y_{1}\right) \approx \frac{1}{G} \sum_{g=1}^{G} \mathbf{1}\left(\hat{Y}_{1, t}^{N,(g)}<Y_{1, t}\right),
$$

where each $\hat{Y}_{1, t}^{N,(g)} g=1,2 \ldots, G$ is a draw from the posterior density $f\left(\hat{Y}_{1, t}^{N} \mid Y_{1}\right)$.

When interpreting the variation in the distribution of the synthetic control outcome, $\hat{Y}_{1, t}^{N}$, it is vital to recognize that the variation stems from two sources. One is the dispersion in the posterior draws of weights, $W$. This dispersion arises due to uncertainty about the correct composition of the synthetic control. The uncertainty is over how one should weight the untreated units. Which of those units' experiences most closely resembles the experience of the treated unit? This uncertainty arises from the pre-treatment period, when one determines the basis for the counterfactual case study. Our method directly estimates this uncertainty, which allows us to distinguish it from the second source of uncertainty. The second source is the post-treatment dispersion in the outcomes for the untreated units. The more these outcomes differ and diverge, the greater the uncertainty about the impact of the treatment.

To illuminate these issues, it is useful to consider the variance of the synthetic control outcome, $\hat{Y}_{1, t}^{N}$, and two examples.

$$
\begin{aligned}
\operatorname{Var}\left(\hat{Y}_{1, t}^{N} \mid Y_{1}\right) & =\operatorname{Var}\left(Y_{0, t} W \mid Y_{1}\right) \\
& =\operatorname{Var}\left(\sum_{j=1}^{J} Y_{0, t, j} w_{j} \mid Y_{1}\right) .
\end{aligned}
$$

Consider the case when $Y_{0, t, j}=\bar{Y}$ for each $j=1,2 \ldots J$ viz., or in other words, when the post-treatment outcomes across all $j$ untreated units at time $t$ are equal. In this case, there is no uncertainty. Regardless of the weights, the synthetic control equals $\bar{Y}$. The posterior variance of $\hat{Y}_{1, t}^{N}$ reduces to 0 on account of the sum-to-one restrictions applicable to the estimated 
parameter vector $W$ as seen below.

$$
\begin{aligned}
\operatorname{Var}\left(\hat{Y}_{1, t}^{N} \mid Y_{1}\right) & =\operatorname{Var}\left(\sum_{j=1}^{J} \bar{Y} w_{j} \mid Y_{1}\right) \\
& =\operatorname{Var}\left(\bar{Y} \sum_{j=1}^{J} w_{j} \mid Y_{1}\right) \\
& =\operatorname{Var}\left(\bar{Y} \mid Y_{1}\right)=0 .
\end{aligned}
$$

Another way of stating this is that the synthetic control lies in the set spanned by the historical experience of the untreated units. If all untreated units had the same experience, they span a set with a single element. So, the synthetic control is known with certainty. Regardless of the weights, it is that element.

Now, consider the case when post-treatment outcomes for untreated units $1,2, \ldots, J_{0}$ are $\bar{Y}$ and for untreated units $J_{0}+1, \ldots J$ are $\ddot{Y}$. Let $\sum_{j=1}^{J_{0}} w_{j}=\bar{w}$. The posterior variance of $\hat{Y}_{1, t}^{N}$ can now be expressed as,

$$
\begin{aligned}
\operatorname{Var}\left(\hat{Y}_{1, t}^{N} \mid Y_{1}\right) & =\operatorname{Var}\left(\sum_{j=1}^{J_{0}} \bar{Y} w_{j}+\sum_{j=J_{0}+1}^{J} \ddot{Y} w_{j} \mid Y_{1}\right) \\
& =\operatorname{Var}\left(\bar{Y} \bar{w}+\ddot{Y}(1-\bar{w}) \mid Y_{1}\right) \\
& =(\bar{Y}-\ddot{Y})^{2} \operatorname{Var}\left(\bar{w} \mid Y_{1}\right) .
\end{aligned}
$$

The variance of $\hat{Y}_{1, t}^{N}$ is clearly an increasing function of the difference between $\bar{Y}$ and $\ddot{Y}$ and also $\operatorname{Var}\left(\bar{w} \mid Y_{1}\right) . \bar{Y}$ is the maximum among untreated units. $\ddot{Y}$ is the minimum among untreated units. The set spanned by the historical experience of the untreated units (i.e. the set of all convex combinations of the untreated units) is the interval between $\bar{Y}$ and $\ddot{Y}$. As the breadth of historical experience expands (i.e. as the width of the interval increases), the variance of our estimate also increases. This relationship extends to the case when the $J$ untreated units have unique values. In general, the dispersion of the counterfactual $\hat{Y}_{1, t}^{N}$ around its posterior mean is jointly determined by the dispersion of posterior draws of $W$ around their posterior means as well as variation in the post-intervention experience of untreated units.

We initially apply our method to Rhode Island's RISDIC crisis. Figure 3 illustrates the weights that we estimate for unemployment and compares them to the weights derived from the classic synthetic control method. The figure plots the marginal posterior density $f\left(W \mid Y_{1}\right)$ for weights assigned to three states. Massachusetts, whose unemployment rate mirrored Rhode Islands in the ten years before treatment, receives substantial weight. Approximately $96 \%$ of the probability mass lies in between .45 and .95 . The expected value of the distribution, which is our point estimate, is 0.688 (dashed vertical line). This is close to 
the original methods' estimate for Massachusetts of 0.641 (dotted vertical line). Michigan is an intermediate case. South Carolina receives little (almost no) weight, because the level and movements in its unemployment rate had little resemblance to those of Rhode Island. For the other 46 states, our point estimates resemble those from the original synthetic control. This resemblance often occurs in our application, but it need not occur. Our objective function and estimation method differ from those of (Abadie and Gardeazabal, 2003). A key difference is $V$, which allows a differential weighting of the contribution of different variables and observations to the estimation of the weights. Another difference is that the original method minimizes the sum of squares of errors, while the Bayesian method numerically integrates over the surface of the parameter space.

We plot the results for unemployment in Figure 4. The top panel depicts Rhode Island's actual unemployment rate, the synthetic control (i.e. our counterfactual estimate of what Rhode Island might have been in absence of treatment), and the posterior probability interval around the synthetic control. The panel illustrates several salient patterns. Unemployment in Rhode Island peaked 18 months into the RISDIC crisis, in the summer of 1992. At that time, the state repaid a substantial share of the deposits that had been frozen since January 1991. Rhode Island's unemployment remained elevated relative to control for the rest of the decade. Rhode Island's unemployment rose outside the $90 \%$ probability interval around the synthetic control in October 1991, ten months after RISDIC's closure, and remained outside the the 99\% probability interval for the next decade. Overall,Rhode Island's payments purgatory raised its unemployment rate about $0.8 \%$ relative to the synthetic control.

The narrowing of the probability interval in 1995 and 1996 reveals how the different sources of variation influence synthetic-control estimates. The posterior density of the weights, depicted in Figure 3, indicates the synthetic control sample loads principally on three states: Massachusetts, Delaware, and Michigan. The level and trend of unemployment rates in these states converged during 1995 and 1996. This convergence limits uncertainty about the synthetic control at that time.

The bottom panel depicts our estimate of the average treatment effect. The treatment's impact arises with a lag. The lag is expected for unemployment, which typically peaks twelve to eighteen months after an adverse shock to the macroeconomy. The probability interval around the average treatment effect initially expands and latter contracts. This reflects a divergence of unemployment rates among untreated states in the early 1990s, when the length and severity of contractions differed across states, and a convergence of unemployment rates in the mid 1990s, as the national economy reached full employment during the decade long economic expansion.

Together, the two panels illuminate why the RISDIC crisis' impact on unemployment persisted for a decade. The dynamic impact of the crisis was as expected. Unemployment 
increased with a lag, peaked, and then returned toward equilibrium. Relative to other controls, however, the impact appears persistent, because Rhode Island's unemployment rate recovered at the same rate as the control states.

Results for labor force participation appear in Figure 5. Our estimate suggests Rhode Island's RISDIC crisis lowered labor force participation substantially and permanently. By 1993, the probability that RISDIC reduced the labor force participation rate (LFPR) exceeds $99.9 \%$. The reduction was substantial. The mean estimate of the average treatment effect for the period 1991 through 1995 (and onward) is about $-2 \%$. The peak effect for some months in 1994 and 1995 is lower than -3\%. The labor force participation rate only rebounds towards the synthetic control at the end of the decade. The rebound was driven by a decline in the denominator, the size of the labor force, as workers left Rhode Island, which was one of the few states in the nation and the only one the Eastern seaboard to lose population during the 1990s. Tracking the initial decline is difficult, due to revisions in labor force participation data in 1992, when the Bureau of Labor Statistics (BLS) revised the series to conform to census industrial classifications introduced in 1990, and again in 1994, when the BLS redesigned the Current Population Survey, from which the LFPR is derived. ${ }^{10}$ In addition, in 1991, Rhode Island established an employment workshare program. It began operations at the end of the year. It allowed pairs of workers to reduce their hours by $50 \%$ and receive unemployment compensation sufficient to provide them with $90 \%$ of normal income. These workers remained listed as in the labor force. In 1992, the program averted 2,173 layoffs, which accounts for 0.4 percentage points of the increase. ${ }^{11}$

Results for gross state product (i.e. GDP per state) appear in Figure 6. The results indicate the probability that the RISDIC crisis reduced Rhode Island's gross domestic product relative to potential is high, about $80 \%$ after 5 years and about $90 \%$ after ten years. The decline relative to controls occurred gradually and appears to have been permanent. This results seem sensible, given that Rhode Island's population declined in absolute terms during the 1990s, as did the size of its labor force and total employment. There is substantial uncertainty about this estimate. Initially (i.e. in 1991), the probability interval is wide. Its width reflects uncertainty over weights for control states and the dispersion of gross output across states. The interval widens as time passes. The width almost doubles in ten years. This expansion reflects increasing differences in output across states. Some state economies grew more slowly in the 1990s. Others grew quicker. The states which grew most rapidly participated in the technology

\footnotetext{
${ }^{10}$ These revisions resulted in a temporary increase in the national LFPR from 1992 to 1994 by 0.7 percentage points. The revision bump for Rhode Island was larger, 1.7 percentage points. We are not sure why. The literature on the revision advises readers to interpret patterns in the linking period (1992 to 1994) with caution, since patterns exhibited in those years may be statistical artifacts that do not reflect economic reality (Cohany, Polivka, and Rothgeb, 1994; Green, 1994; Polivka, 1996).

${ }^{11}$ In September 1991, when the program began operations, Rhode Island's labor force was 515,229. Senate Finance Committee, Fogarty (2011) Testimony.
} 
and finance booms at the end of the millennia. These booms were concentrated in a few states (Uhlenkott, 2014). These concentrated booms, which caused states' aggregate outputs to diverge, complicate efforts to determine how Rhode Island's economy would have evolved in the absence of the RISDIC crisis. Small changes in synthetic control weights can change the counterfactual substantially. Our baseline synthetic control places substantial weight on states, like Maine, that did not participate in the tech and finance booms, and place little weight on states, like California and Massachusetts, that did. For this reason, there is a high likelihood that the RISDIC crisis reduced Rhode Island's GDP by a small amount, because if the RISDIC crisis had not occurred, Rhode Island's economy would probably have performed like a state that missed the tech and finance booms. There is a low probability that the RISDIC crisis reduced Rhode Island's GDP substantially, because in the absence of the RISDIC crisis, Rhode Island's economy might have taken off. This possibility seems plausible. The RISDIC crisis hit in early 1990s, just when the booms in tech and finance began. Rhode Island's highly educated labor force might have been an attractive place for tech firms to locate. Rhode Island has great universities. It is near New York and Boston, but has lower real estate prices than those urban hubs to the north and south along interstate 95. High tech firms, however, did not locate in Rhode Island, whose economies is one of the least tech intensive in the US today. Our estimates say it's possible that the RISDIC crisis caused it to miss out on this opportunity, which is why the probability interval is wide, and why the crisis could have had a large effect reducing output relative to what might have been if the crisis had not induced entrepreneurs who might have set up shop in Rhode Island to set up shop elsewhere.

Results for ten series that we analyze for Rhode Island are summarized in Table 2. For each series, the table indicates the average treatment effect (ATE) and the probability of an adverse outcome relative to controls at two and five years after RISDIC's failure in Rhode Island. The formula for the average treatment effect is Equation (5). The formula for the probability is Equation (7). Our measure of an adverse shock is an average treatment effect for five years after the crisis consistent with deteriorating economic conditions. Examples include an increase in unemployment in the treated state relative to controls, or a decline in output in the treated state relative to controls. The first row of the table indicates that from January 1991 to January 1993, unemployment in Rhode Island was on average 0.63 percentage points higher than in controls. The probability that unemployment increased (i.e. ATE > 0) rounds to $100.0 \%$ at one decimal place (i.e. prob > 99.95\%). From January 1991 to January 1996, unemployment in Rhode Island was on average 0.94 percentage points higher than in controls. The probability that unemployment increased in that span also rounds to $100.0 \%$ at one decimal place. For most series after five years, the probability of an adverse shock exceeds $99 \%$. The exceptions are gross state product, per capita personal income, employment, and population. For all of those series, the probability of an adverse shock exceeds $75 \%$. 
Our estimates do not directly yield the probability that all of the data series that we examine exhibit an adverse shock after the financial crisis. After specifying an assumption on the dependence structure across economic aggregates, however, our methods yield a lower and an upper bound for the simultaneous occurrence of adverse shocks. These appear in the bottom rows of Table 2. The assumption is that the adverse shocks across economic aggregates for a state are not negatively dependent. The assumption is, in other words, that an adverse shock increasing unemployment (which would be bad) does not increase the probability of a positive shock to output (which would be good). Given that assumption, the lower bound is the product of the probabilities of an adverse treatment effect at a point in time for all of the series for a state. The lower bound corresponds to a scenario when adverse shocks are independent across series. The upper bound is the lowest probability of an adverse shock across economic series for each state. The upper bound corresponds to a dependence structure in which an adverse shock striking the outcome least likely to be afflicted entails that all other series are impacted with certainty. The higher the probability that an adverse shock to one series would coincide with adverse shocks to the other series, the closer reality would lie to the upper bound. Our calculation indicates that there is a substantial probability the RISDIC crisis in Rhode Island triggered an adverse shock in all of the series that we examine. If one loosens the criteria for the calculation to determine the probability that the RISDIC shock triggered adverse shocks in all but one or two series, the probability rapidly approaches $100 \%$.

Table 3 summarizes the same information for Maryland, Ohio, and Nebraska after their payments crises. The results appear consistent with our initial observation that payments crises did not appear to harm the economies in those states. The preponderance of the ATEs that we measure are small. The majority are consistent with economic expansion, rather than contraction. Probabilities of adverse outcomes are usually below $40 \%$ and often near $0 \%$. At most time horizons, the probability that the payments crises simultaneously triggered adverse shocks to all of the series we examine rounds to zero at the third to fifteenth decimal place. If one loosens the criteria for the calculation to determine whether the probability that the payments crises in those states triggered adverse shocks in all but one or two data series, the probability remains near zero. If one calculated the probability of a simultaneous salutary shock to these series, the probability is also near zero. The conclusion is clear. No systematic relationship between macroeconomic aggregates and the payments crises in Maryland, Ohio, and Nebraska exists.

Table 4 examines changes in sectoral GDP in the four states following their payments shocks. In Rhode Island after five years, the probability that the most strongly cyclical components of GDP - manufacturing, wholesale trade, and retail trade - declined relative to controls ranged from $99 \%$ to $100 \%$. FIRE (finance, insurance, and real estate) and services (broadly defined) also move procyclically, but typically less than manufacturing and trade. The proba- 
bility that they declined due to the RISDIC crisis was $97 \%$ and $86 \%$ respectively. The probability that all of these sectors simultaneously experienced adverse shocks is from $82 \%$ to $86 \%$. The magnitudes of these declines (as exhibited by the average treatment effect) was large. The construction sector did not decline, but this should be expected, because the Federal Reserve's response to Rhode Island's crisis substantially expanded mortgage credit available in the state, by encouraging federally-regulated financial institutions to expand lending for residential and commercial real estate (we discuss this more in the next section). The acyclical components of GDP changed little. Their average treatment effects and the probability of adverse outcomes were small. These patterns, according to Stock and Watson (1999, p. 39), resemble correlations typical of downturns driven by declines to aggregate demand. Our findings show that the lower quantiles of the counterfactuals for GSP in Figure $6 \mathrm{~b}$ become pertinent. The larger decline relative to potential GSP arises from Rhode Island missing out on the finance boom. The findings in Table 4 show that this was a likely outcome of the payments crisis.

In Maryland, Nebraska, and Ohio, the ATEs and probabilities of adverse shocks for components of GDP that typically vary with the business cycle were lower. For many variables, the ATEs were inconsistent with those expected of adverse shocks to the aggregate economy. The probability that these series exhibit simultaneous adverse shocks is low, usually close to zero. These results indicate the payments crises in these states had little impact on macroeconomic aggregates.

\section{Robustness}

When we consider the robustness of our estimates, we need to consider threats to inference of several types. The first is whether our estimates for Rhode Island really detect a macroeconomic impulse that simultaneously impacts all macroeconomic time series, and if so, whether we can measure that common shock and its reflection in a common weighting across untreated units. The second is whether alternative explanations exist for the patterns that we observe in the data. Could something other than the RISDIC crisis, for example, explain the divergence of Rhode Island's macroeconomics aggregates from comparable states in the early 1990s? The third involves assumptions underlying estimates presented in the paper and our syntheticcontrol methods. Do our estimates depend upon particular assumptions? Would our results change if we altered the method for synthetic control weights? Examples include altering the length of the pre-treatment comparison period, from say five to ten years, or changing the variables that we use to generate weights. This issue, we will show, encompasses the topic of pretrends. The fourth is whether the patterns that we detect in aggregate data also appear in information at lower levels of aggregation.

The robustness checks that we present focus on Rhode Island. These checks corroborate 
the conclusion that Rhode Island's payments crisis adversely affected the state's economy. We present few checks for the other states, since their payments crises do not appear to have had substantial effects on their aggregate economies.

\subsection{Common Shock}

To determine whether a macroeconomic shock coincided with the payments crises in the four states, we calculate the first principal component of the macroeconomic aggregates for each state before the date of their crisis and also the first principal component for all other states up to that point in time. The first principal component is a weighted average of the series that explains the maximum variance among them. Across the board, we find these first principal components were positively related to employment, labor force participation, and gross state product, and negatively related to unemployment. When the first principal component increased, in other words, a state's economy was doing better. When the first principal component declined, a state's economy was doing worse.

For each payments crisis, we construct a synthetic control from the first principal components of the untreated states. Figure 7 reveals the results of the exercises. Each panel plots the first principal component for a state versus its synthetic control. The panels provide a clear message. After the payments crisis in Rhode Island, the macroeconomic conditions deteriorated immediately, substantially, and persistently in absolute terms and relative to its control. The payment's crisis, in other words, harmed Rhode Island's economy. In contrast, after the payments crises in Maryland, Nebraska, and Ohio, macroeconomic conditions did not decline in absolute terms. In Maryland, macroeconomic conditions improved relative to control. In Nebraska, macroeconomic conditions moved in tandem the control for eight years and then rose. In Ohio, macroeconomic conditions moved along with the control for three years and then shifted downwards slightly.

The common shock's impact on the original series can calculated by substituting the distributions of weights from our principal components analysis into the formulas used to calculate Table 2 and Table 3. This substitution replaces the weights estimated individually for each series with weights for the common shock. For Rhode Island, the weights for the common shock emphasize New Hampshire (posterior mean $=52.4 \%)$, Vermont $(10.0 \%)$, Indiana $(24.0 \%)$, and Michigan (13.6\%). The substitution does not alter our conclusions. For Rhode Island, for example, the ATE for unemployment at five years rises to 1.98 percentage points and the probability of an adverse ATE rounds to $100 \%$. The ATE for labor force participation at five years falls to -4.2 percentage points and the probability of an adverse ATE rounds to $100 \%$. These ATE's are more adverse than in our series-by-series estimates, but the overall pattern remains the same. When we do this exercise for Maryland, Ohio, and Nebraska, average 
treatment effects and probabilities of adverse impact change little, usually shifting slightly towards zero. For unemployment after five years, for example, the ATEs for Maryland, Ohio, and Nebraska become $-0.01,-0.38$, and -2.06 . The probability that the ATE exceeded zero (i.e. the probability of an adverse event) fell to $4.6 \%$ and $0.0 \%$ in the latter states.

\subsection{Alternative Explanations}

Our argument rests, in part, on our assertion that the payments crisis was the only event in early 1991 that affected Rhode Island's macroeconomy relative to control states. Could something else explain the patterns that we see in the data? Perhaps due to an unobserved difference between labor-market institutions in Rhode Island and other states, unemployment in Rhode Island always recovers slower than in other states. Figure 8 addresses this issue. It uses the synthetic control method underlying Figure 1a to calculate similar statistics with the treatment dates set to July 1981 and November 1982, the two previous NBER businesscycle troughs, and August 1980 and September 1982, the two previous months of maximum unemployment in Rhode Island. After these four placebo treatment dates, unemployment in Rhode Island recovers more quickly than in the synthetic controls. This pattern also emerges when you compare Rhode Island to raw or population-weighted averages of all states, of states with occupational structures similar to Rhode Island, or of states in New England. During the two recessions prior to RSDIC's failure, for example, unemployment in Rhode Island recovered more rapidly than unemployment in all other states in New England. The post-RSDIC pattern in Rhode Island, in other words, differed from the pattern observed during all other recessions observable in unemployment data aggregated at the state-month level. After RSDIC, Rhode Island recovered slower than other states. After all other contractions, Rhode Island recovered quicker. From this, we conclude the patterns that we observe in 1991 were not due to some persistent feature of Rhode Island. Rhode Island's post-RISDIC experience was a unique.

Another possible explanation for Rhode Island's deepening contraction in 1992 is the credit crunch afflicting New England at that time (Bernanke and Lown, 1991). Perhaps the credit crunch continued in Rhode Island while easing in other states? Table 5 addresses this possibility. In 1990, Rhode Island's decline in total lending was about average for New England. In 1991, lending continued to decline in northeastern states, but after the RISDIC crisis in Rhode Island, total lending rose. The largest increases came in real estate (i.e. mortgage) lending. The expansion was the result of the federal response to the crisis. The Federal Reserve, Federal Deposit Insurance Corporation, and the Comptroller of Currency knew that the lenders closed during the RISDIC crisis emphasized real-estate lending. The preponderance of their portfolios (over 90\%) consisted of residential and commercial mortgage loans. To offset the closure of these institutions, the federal agencies encouraged intermediaries under their 
jurisdiction to expand real-estate lending in Rhode Island and lifted regulatory constraints on lending of this type. Federally-insured institutions responded by filling the gap. Lending on real estate expanded.

Consumer lending, however, shrank substantially. The decline was not due to a contraction in loan supply, since the institutions caught up in the RISDIC crisis did little consumer lending, and alternative suppliers of consumer loans, such as issuers of credit cards and auto loans, were large, healthy, competitive, and encouraged by regulators to extend loans in Rhode Island. This includes federally-insured institutions in the state, which continued operations uninterrupted, and out-of-state organizations, including those that operated nationwide.

While Rhode Island's unemployment increase after RISDIC's failure in 1991 seems consistent with unemployment's response to an aggregate impulse (such as a decline in demand due to consumers losing access to a substantial share of their liquid assets), we still need to ask if the increase could have been caused by other policy changes in Rhode Island at that time. The synthetic-control method itself cannot distinguish between competing explanations for a divergence detected at a point in time. We have examined historical sources - including Rhode Island's state budget, its Governors' speeches and policy pronouncements, and records of the state legislature - to determine other potential candidates. One possibility is apparent. Four months after the start of the RISDIC crisis, Rhode Island raised its minimum wage on April 1, 1991, to $\$ 4.45$ from $\$ 4.25$ per hour.

Could this increase in the minimum wage explain the patterns that we observe? It is unlikely for several reasons. First, in April 1991, when Rhode Island raised its minimum wage by $\$ 0.20$ per hour, its minimum wage rate fell $\$ 0.25$ relative to most other states, including Massachusetts and New Hampshire, because the federal government raised the minimum wage by $\$ 0.45$ per hour at that time. So, if the minimum wage had the same impact on unemployment in all states, it should have lowered Rhode Island's unemployment rate relative to other states, rather than increased it, as we observe. Second, there is a debate about the impact of minimum wages. Recent articles find no relationship between small increases in minimum wages and state-level employment and unemployment (Dube, Lester, and Reich, 2010). The largest recent estimates of minimum wages' marginal impact on employment indicate that Rhode Island's small minimum-wage hike could not explain the large and persistent increase in unemployment after RISDIC's failure and cannot explain the sectoral distribution that we describe later in the paper (Neumark and Wascher, 2000). Third, we find substantial post-RISDIC changes relative to controls in a broad range of macroeconomic aggregates for Rhode Island, including bankruptcies, construction, industrial production, and mortgage delinquencies. There is no evidence to suggest and no reason to believe that small increases in minimum wages would have such effects. Fourth, a series of placebo tests indicate that after increases in minimum wages in absolute terms, relative to Massachusetts, and relative to the 
rest of the United States, unemployment in Rhode Island typically changed little or declined. For these reasons, it seems unlikely that Rhode Island's minimum wage policies triggered the increase in unemployment observed in Rhode Island in 1991 and afterwards.

\subsection{Assumptions and Pretrends}

Our synthetic control estimates, like all others, depend upon assumptions that shape estimation of control weights for comparison units. These assumptions include the length of the pre-treatment period, the variables used to compare treated to untreated units in the pretreatment period, the set of untreated units considered for comparison, and the method used to make the comparison. Altering these assumptions might change our estimates or their interpretation.

On each of these dimensions, we have checked the range of reasonable assumptions, and believe that altering our assumptions over this range does not effect our analysis. Section 2, our first look at the data, eludes to one check. We have used several different methods of inference in synthetic controls and recovered similar results (Li, 2019; Chernozhukov, Wuthrich, and $\mathrm{Zhu}, 2019)$. The robustness exercise above - where we examine common macro shocks - eludes to another range of checks, where we derive weights using a broader set of pre-treatment variables. We find this does not change our results.

The results on another dimension of checks deserves emphasis. Varying the length of the pre-treatment period has little impact on ATEs estimated for Rhode Island, but it does alter the weights assigned to untreated states. Shortening the pre-treatment period in all cases increases weights assigned to states in New England and reduces weights assigned to other states. Our analysis of unemployment is an example. When we shorten the pre-treatment interval to 36 months, weights increase on Massachusetts and New Hampshire and diminish on all other states. The posterior mean for Massachusetts becomes $92.9 \%$. The posterior mean for New Hampshire becomes 7.1\%. All other posterior means approach zero. Weights converge on Massachusetts and New Hampshire because Rhode Island shared a regional boom and bust with them in the later 1980s, and the regional pattern at this time differed from the regional distribution of shocks during the previous business cycle in the early 1980s.

The results of this exercise for unemployment appear in Figure 9. The figure reveals two important points. First, in some specifications presented earlier in the paper, unemployment appears to rise in Rhode Island relative to controls prior to the RISDIC crisis. This apparent pre-treatment trend arose when the infamous credit crunch in New England took hold, and the recession deepened in Rhode Island relative to states outside New England. By limiting the pre-treatment window, we emphasize Rhode Island's comparison to New England states, and the apparent foreshock disappears. Rhode Island's unemployment rate parallels or con- 
verges on the synthetic control as the treatment approaches. Rhode Island's unemployment rate diverges from control nine months into the crisis. This pattern is consistent with the conventional view of unemployment's response to aggregate demand shocks. The impact should be lagged. It should peak eighteen to twenty-four months into a contraction. We also see that narrowing the pre-treatment window increases the estimated ATE for unemployment. These patterns hold for most of the variables that we examine.

\subsection{County-Level Comparisons: Border Discontinuity and Synthetic Con- trols}

Since shortening the pre-treatment window emphasizes the comparison between Rhode Island and its neighbors, it is reasonable to ask: what would result from a direct comparison between Rhode Island and its neighbors in New England? We can do this with data on county business pattern. This data set indicates total employment and number of establishments on March 12 of each year. Figure 10 displays data for Providence, Rhode Island, and neighboring counties in Connecticut, Massachusetts, and Rhode Island. Among counties in Rhode Island, Providence was the hardest hit in terms of the number of frozen institutions, dollars in frozen deposits, frozen deposits per capita, and length of time that deposits remained frozen. In the counties of Bristol and Kent, only a handful of institutions shut down and those reopened within a few weeks.

The impact of the RISDIC crisis varied across these counties and their neighbors in adjacent states. From 1989 to 1991, all of these counties experience sharp contractions in employment and establishments. In all of these counties except Providence, recovery began in 1991 and is visible by 1992. In Providence, however, recovery was delayed, and Providence's recovery lagged far behind neighboring counties throughout the 1990s.

Figure 11 displays a similar result that arises from synthetic-control analysis conducted on county-level data. We present results for employment and the number of establishments. This exercise uses the same methods as our state-level analysis, but for computational reasons, we limit the analysis to 50 counties whose occupational and industrial structures most closely matched Rhode Island's. For Providence, the county most effected by the RISDIC crisis, we find the probability of an adverse ATE after five years to be over 95\%. For Rhode Island counties unaffected by the RISDIC crisis, we recover ATEs near zero. From this, we conclude that county-level synthetic control analysis and county-level border-discontinuity analyses corroborate our result for state-level aggregates. 


\section{An Application to the 2008 Financial Crisis}

Our essay began with quotes from central bankers who argue that in the fall of 2008, the Fed had to take extraordinary actions because the financial tsunami threatened to engulf the commercial banking system, which could have devastated the aggregate economy, as like the bank suspensions during the 1930s. Rhode Island's governor faced a choice, bail out the banks immediately to ensure households and firms retained access to deposit balances, or close the banking system, until courts and politicians resolved debates about who would pay the price to clean up the mess. Rhode Island chose the latter course. In 2008, the Fed's leaders chose the former. What if they made the other choice?

Rhode Island serves as a unique analogy which can help to answer that question. The magnitude and length of Rhode Island's banking suspension in 1991 resembled those during the Great Depression. Its recession, like the contractions of 1929-1933 and 2007-2009, was born in a lending boom and exacerbated by a credit crunch. So, Rhode Island's experience can help us address the question: what would have happened to the U.S. economy in the years after the financial crisis of 2008 if the federal government refused to bail out AIG and the commercial banks dependent on it, forcing some or all of them to suspend payments on deposits for a few weeks or months, just like banks did during the Great Depression of the 1930s?

The answer appears in Table 6. The table examines seven data series which we observe at the state and national level from 1980 to 2013. The first column indicates the actual value of the national series in December 2010. In that month, for example, the national unemployment rate was $9.3 \%$. The next four columns indicate potential impacts of a commercial-banking crisis derived from probability distributions that we for Rhode Island's RISDIC crisis. Columns (2) to (5) and (7) to (10), labelled "Counterfactual Value at Probability Threshold", indicate that the adverse outcome equaled or exceeded the indicated value with the probability indicated at the top of the column. The second column indicates, for example, that after a nation-wide commercial banking crisis comparable to RISDIC, the unemployment rate would reach $10.2 \%$ or higher with probability $75 \%$. The first four rows display rates: unemployment, mortgages past due, bankruptcies (per thousand persons), and labor force participation. Our estimates of counterfactual rates indicate the recession would have been deeper, but the economy would recover. By 2013, five years after the crisis, bankruptcies, mortgages past due, and unemployment would be falling towards pre-recession levels. Labor force participation, however, might not have recovered. The probability that the LFPR fell below $60 \%$ exceeded $75 \%$. With so many workers leaving the labor force, it should be no surprise that our estimates indicate that there was the risk of substantial declines employment and output, both in the short (2-year) and medium (5-year) runs, and perhaps permanently, if a commercial banking shutdown rivalling those of the Great Depression struck the United States during the Global Financial Crisis in 
2008 and 2009.

Is this analogy plausible? It depends, of course, on whether the factors effecting Rhode Island in the 1990s and the sources of uncertainty in our estimates had analogs at the national level in 2008 and the decade after. The decline in employment in Rhode Island was driven by a reduction in the labor force participation rate, which did occur nationally during the Great Recession, and a decline in working age population, which appears to be less plausible. Rhode Island shed population because workers and retirees moved to other states and fewer men and women moved in to replace them. At the national level, it seems unlikely that workers and retirees would have departed from the United States, but given events during recent years and American history, it seems possible that immigration restrictions could have been imposed in the wake of the crisis, which would have reduced inflows of workers, leading to a decline in employment on aggregate. This has happened in the past. In the 1870s, 1880s, and 1920s, waves of anti-immigration agitation and immigration restrictions followed years of recession and deflation. The decline in output relative to what might have been in Rhode Island was a product of the hi-tech and finance booms of the 1990s. Rhode Island missed these booms, while these increasing-returns industries became increasingly important economic sectors in neighboring states. It seems possible that this could have happened to the United States after 2008, if a prolonged shutdown of money-center banks encouraged financial institutions to shift activity from New York to London or Tokyo, and if political uncertainty, erratic economic

policies, and immigration restrictions deterred investment and induced hi-tech firms to shift operations towards Europe and Asia.

\section{Discussion}

This paper studies modern episodes of suspension of payments to ascertain how shutting down the commercial banking system influences aggregate economic activity. The suspension in Rhode Island, which coincided with an economic contraction, increased unemployment and reduced output. The suspensions triggered reductions in output in sectors typically impacted by declines in aggregate demand. The effects persisted for at least ten years. Some may be permanent. The suspensions in Maryland, Ohio, and Nebraska, which occurred during economic expansions, appear to have had no systematic impact on the macroeconomy. These results suggest that suspensions of payments - particularly those like Rhode Island's which freeze a substantial fraction of liquid assets for a long period of time - can trigger reductions in spending on goods and services that have lasting economic effect.

Our findings have implications for the broader debate on financial regulation and bank bailouts. Advocates of the current approach assert that it is vital to keep commercial banks in operation in all states of the world. As evidence, they point to our economy's experience with 
suspensions of payments a century ago and to developing economies experience with banking crises in recent decades. Critiques question the relevance of this evidence to the United States economy today. We provide new information. We show that the old problem - suspensions of commercial bank operations during contractions - can occur in U.S. today, and when it does, is likely to have a substantial adverse impact on our economy. These findings help to validate the use of the costly measures by the Federal Reserve and the Treasury to safeguard commercial banks following the closure of Lehman Brothers in the fall of 2008 and during the COVID-19 contraction in the spring of 2020.

\section{References}

Abadie, A., A. Diamond, and J. Hainmueller (2010). "Synthetic Control Methods for Comparative Case Studies: Estimating the Effect of California's Tobacco Control Program". Journal of the American Statistical Association 105.490, pp. 493-505.

- (2015). "Comparative Politics and the Synthetic Control Method". American Journal of Political Science 59.2, pp. 495-510.

Abadie, A. and J. Gardeazabal (2003). "The Economic Costs of Conflict: A Case Study of the Basque Country". American Economic Review 93.1, pp. 113-132.

Aitchison, J. (1982). "The statistical analysis of compositional data". Journal of the Royal Statistical Society: Series B (Methodological) 44.2, pp. 139-160.

Arkhangelsky, D., S. Athey, D. A. Hirshberg, G. W. Imbens, and S. Wager (2019). Synthetic

Difference In Differences. Working Paper 25532. National Bureau of Economic Research.

Batkins, S. and I. Brannon (2013). "The unknown costs of Dodd-Frank". Regulation 36, p. 4.

Beaudry, P., D. Galizia, and F. Portier (Mar. 2017). “Reconciling Hayek's and Keynes' Views of Recessions". The Review of Economic Studies 85.1, pp. 119-156.

- (2020). "Putting the Cycle Back into Business Cycle Analysis". American Economic Review 110.1, pp. 1-47.

Ben-Michael, E., A. Feller, and J. Rothstein (2018). The Augmented Synthetic Control Method.

- (2019). Synthetic Controls and Weighted Event Studies with Staggered Adoption.

Bernanke, B. and C. S. Lown (1991). "The Credit Crunch". Brookings Papers on Economic Activity 22.2, pp. 205-248.

Bernanke, B. S. (2013). The Federal Reserve and the Financial Crisis. Princeton University Press.

Bethune, Z., G. Rocheteau, and P. Rupert (2015). "Aggregate unemployment and household unsecured debt". Review of Economic Dynamics 18.1. Money, Credit, and Financial Frictions, pp. $77-100$.

Born, B., G. J. Müller, M. Schularick, and P. Sedláček (May 2019). “The Costs of Economic Nationalism: Evidence from the Brexit Experiment*". The Economic Journal 129.623, pp. 27222744. 
Born, B., G. J. Müller, M. Schularick, and P. Sedláček (2020). "Stable Genius? The Macroeconomic Impact of Trump". Journal of Money, Credit and Banking.

Calomiris, C. W. (1993). "The decline of private deposit insurance in the United States: A comment". Carnegie-Rochester Conference Series on Public Policy 38, pp. 129-142.

Carlson, M., K. J. Mitchener, and G. Richardson (2011). “Arresting banking panics: Federal Reserve liquidity provision and the forgotten panic of 1929". Journal of Political Economy 119.5, pp. 889-924.

Chabot, B. R. (2011). "The Cost of Banking Panics in an Age before "Too Big to Fail"'". Federal Reserve Bank of Chicago Working Paper.

Chernozhukov, V., K. Wuthrich, and Y. Zhu (2018). "An exact and robust conformal inference method for counterfactual and synthetic controls". arXiv preprint arXiv:1712.09089.

- (2019). "Practical and Robust t-test based inference for synthetic controls and related methods".

Cochrane, J. H. (2014). “Challenges for Cost-Benefit Analysis of Financial Regulation”. The Journal of Legal Studies 43.S2, S63-S105.

Cohany, S. R., A. E. Polivka, and J. M. Rothgeb (1994). "Revisions in the current population survey effective January 1994". Emp. E Earnings 41, p. 13.

Cohen, J., K. Hachem, and G. Richardson. (2020). "Relationship Lending and the Great Depression". Review of Economics and Statistics.

Davison, L. K. and C. D. Ramirez (2014). "Local banking panics of the 1920s: Identification and determinants". Journal of Monetary Economics 66, pp. 164-177.

Dube, A., T. W. Lester, and M. Reich (2010). "Minimum Wage Effects Across State Borders: Estimates Using Contiguous Counties". The Review of Economics and Statistics 92.4, pp. 945964.

English, W. B. (1993). “The decline of private deposit insurance in the United States". CarnegieRochester Conference Series on Public Policy 38, pp. 57 -128.

Fogarty, C. J. (2011). Testimony before the Senate Finance Committee on the Success of the Rhode Island WorkShare Short-Term Compensation Program, November 10, 2011. Washington: U.S. GPO.

Garcia, P. (2019). “The Macroeconomic Consequences of Bank Capital Requirements”. Annals of Economics and Statistics 135, pp. 157-187.

Geithner, T. F. (2014). Stress Test: Reflections on Financial Crises. Broadway Books.

Gorton, G. and E. W. Tallman (2016). How Did Pre-Fed Banking Panics End? Tech. rep. National Bureau of Economic Research.

Green, G. P. (1994). "Revisions in the Presentation of Data in Employment and Earnings". Emp. $\mathcal{E}$ Earnings 41, p. 8.

Greenspan, A. (2008). The Age of Turbulence: Adventures in a New World. Penguin.

Guerrieri, V. and G. Lorenzoni (2009). "Liquidity and Trading Dynamics". Econometrica 77.6, pp. 1751-1790. 
Guerrieri, V. and G. Lorenzoni (Mar. 2017). "Credit Crises, Precautionary Savings, and the Liquidity Trap*". The Quarterly Journal of Economics 132.3, pp. 1427-1467.

House of Representatives (1991a). Closure of 45 privately insured financial institutions in Rhode Island: hearing before the Subcommittee on General Oversight and Investigations of the Committee on Banking, Finance, and Urban Affairs, House of Representatives, One Hundred Second Congress, first session, April 17, 1991. Washington: U.S. GPO.

- (1991b). Rhode Island banking crisis: field hearing before the Committee on Banking, Finance and Urban Affairs, House of Representatives, One Hundred Second Congress, first session, May 24 and 25, 1991. Washington: U.S. GPO.

Jalil, A. J. (2015). "A New History of Banking Panics in the United States, 1825-1929: Construction and Implications". American Economic Journal: Macroeconomics 7.3, pp. 295-330.

Kashyap, A., J. C. Stein, and S. G. Hanson (2010). “An Analysis of the Impact of 'Substantially Heightened' Capital Requirements on Large Financial Institutions". Mimeo.

Kisin, R. and A. Manela (2016). "The Shadow Cost of Bank Capital Requirements". The Review of Financial Studies 29.7, pp. 1780-1820.

Komai, A. and G. Richardson (2011). A Brief History of Regulations Regarding Financial Markets in the United States: 1789 to 2009. Working Paper 17443. National Bureau of Economic Research.

Lagos, R. and R. Wright (2005). "A Unified Framework for Monetary Theory and Policy Analysis". Journal of Political Economy 113.3, pp. 463-484.

Li, K. T. (2019). "Statistical Inference for Average Treatment Effects Estimated by Synthetic Control Methods". Journal of the American Statistical Association 0.0, pp. 1-16.

Lucas, D. (2019). "Measuring the Cost of Bailouts". Annual Review of Financial Economics 11.1, pp. 85-108.

McKelvey, E. F. (1978). "Interest Rate Ceilings and Disintermediation". Board of Governors Staff Economic Studies.

Mortensen, D. T. and C. A. Pissarides (1994). "Job Creation and Job Destruction in the Theory of Unemployment". The Review of Economic Studies 61.3, pp. 397-415.

Neumark, D. and W. Wascher (2000). "Minimum Wages and Employment: A Case Study of the Fast-Food Industry in New Jersey and Pennsylvania: Comment". The American Economic Review 90.5, pp. 1362-1396.

Poirier, D. J. (1995). Intermediate Statistics and Econometrics: A Comparative Approach. MIT Press.

Polivka, A. E. (1996). "Data watch: The redesigned current population survey". Journal of Economic Perspectives 10.3, pp. 169-180.

Pulkkinen, T. E. and E. S. Rosengren (1993). "Lessons from the Rhode Island banking crisis". New England Economic Review May, pp. 3-12.

Richardson, G. (2007). "Quarterly data on the categories and causes of bank distress during the Great Depression, 1929-1933". Ed. by A. J. Field, G. Clark, and W. A. Sundstrom. Vol. 25. Research in Economic History. Emerald Group Publishing Limited, pp. 69-147. 
Richardson, G. and T. Sablik (2015). "Banking Panics of the Gilded Age". Federal Reserve History (December).

Richardson, G. and W. Troost (2009). "Monetary Intervention Mitigated Banking Panics during the Great Depression: Quasi-Experimental Evidence from a Federal Reserve District Border, 1929-1933". Journal of Political Economy 117.6, pp. 1031-1073.

Rocheteau, G. and R. Wright (2005). "Money in Search Equilibrium, in Competitive Equilibrium, and in Competitive Search Equilibrium". Econometrica 73.1, pp. 175-202.

Sprague, O. M. (1910). "History of Crises under the National Banking System, National Monetary Commission". 61st Congress, 2nd Session, Senate document. 538.

Stock, J. H. and M. W. Watson (1999). "Forecasting Inflation". Journal of Monetary Economics 44.2, pp. $293-335$.

Todd, W. F. (1994). Similarities and dissimilarities in the collapses of three state-chartered private deposit insurance funds. 9411. Federal Reserve Bank of Cleveland, Research Department.

Uhlenkott, B. (2014). "High-Tech Industries in the U.S. Economy". Workforce Information Council High-Tech Study Group, pp. 1-27.

Wasmer, E. and P. Weil (2004). "The Macroeconomics of Labor and Credit Market Imperfections". American Economic Review 94.4, pp. 944-963.

Wicker, E. (2000). Banking Panics of the Gilded Age. Cambridge University Press. 


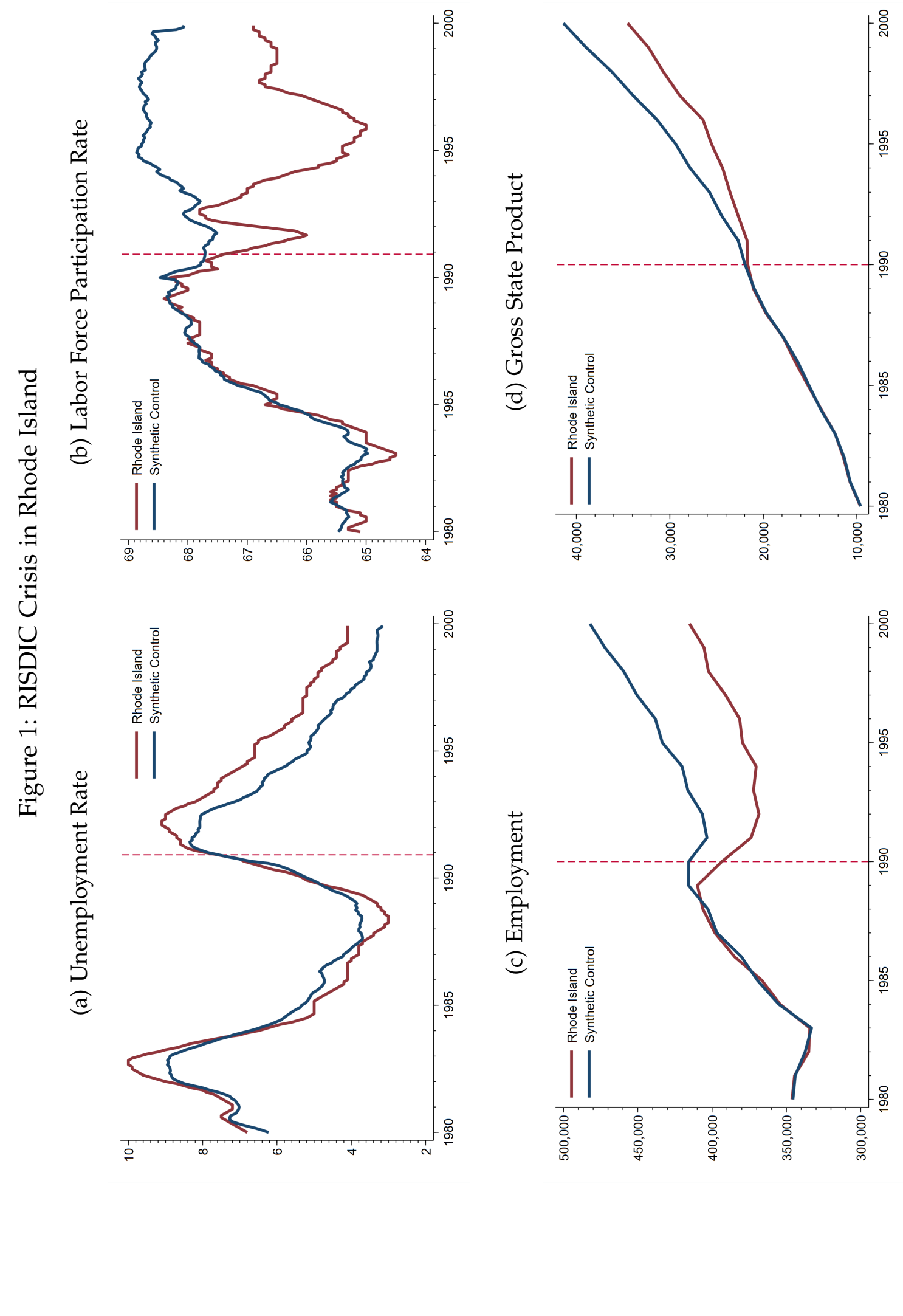


Figure 2: Suspension Crises in Four States

(a) Unemployment Rate

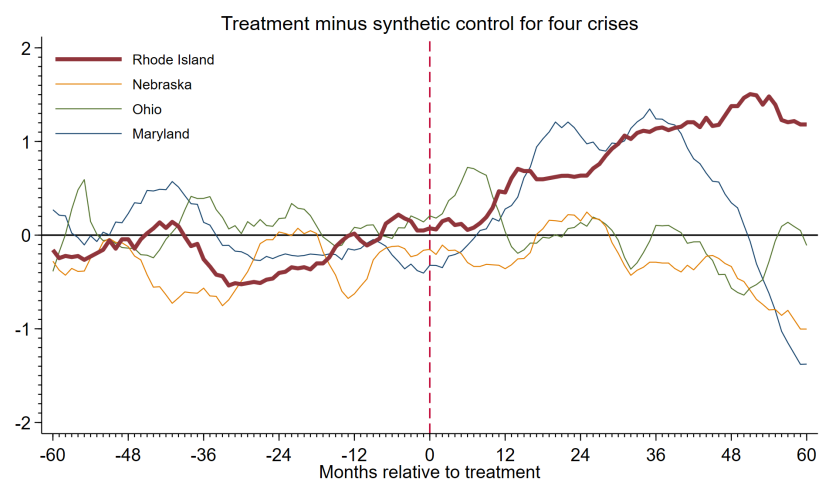

(c) Employment

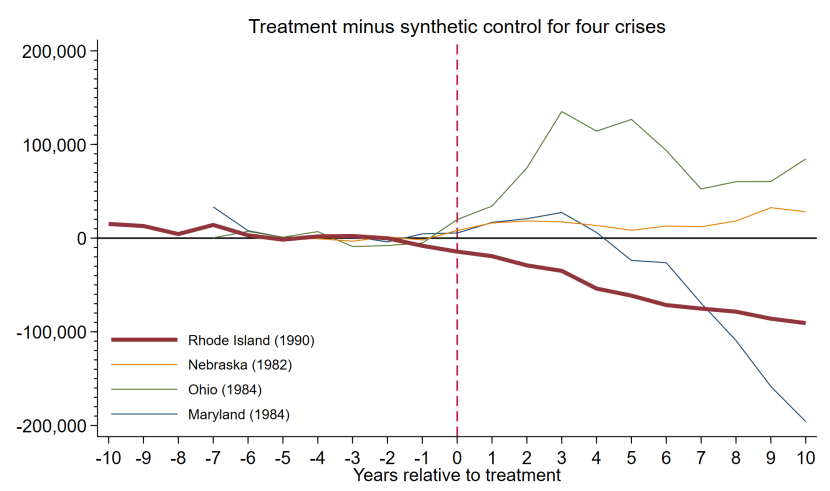

(b) Labor Force Participation Rate

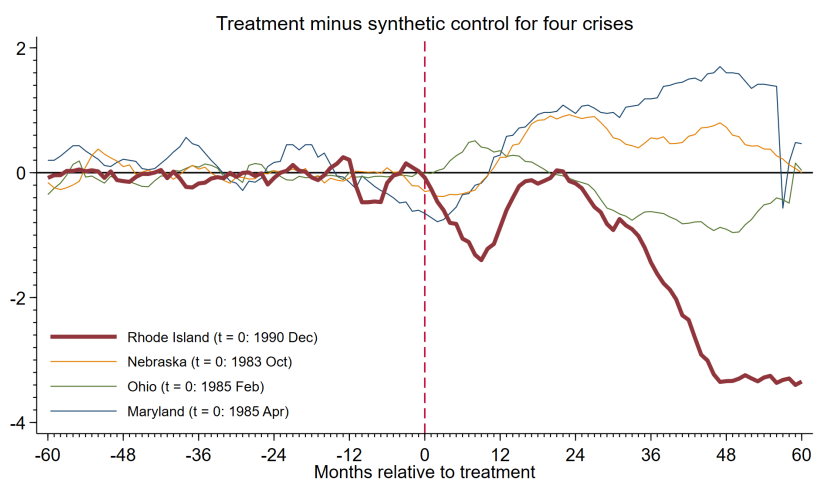

(d) Gross State Product

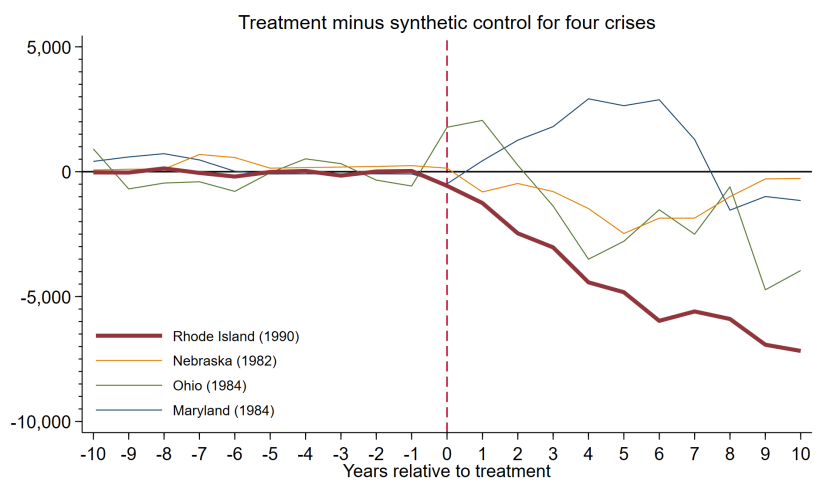

Figure 3: Bayes Weights Distribution in Unemployment Synthetic Control
(a) Massachussetts
(b) Michigan
(c) South Carolina
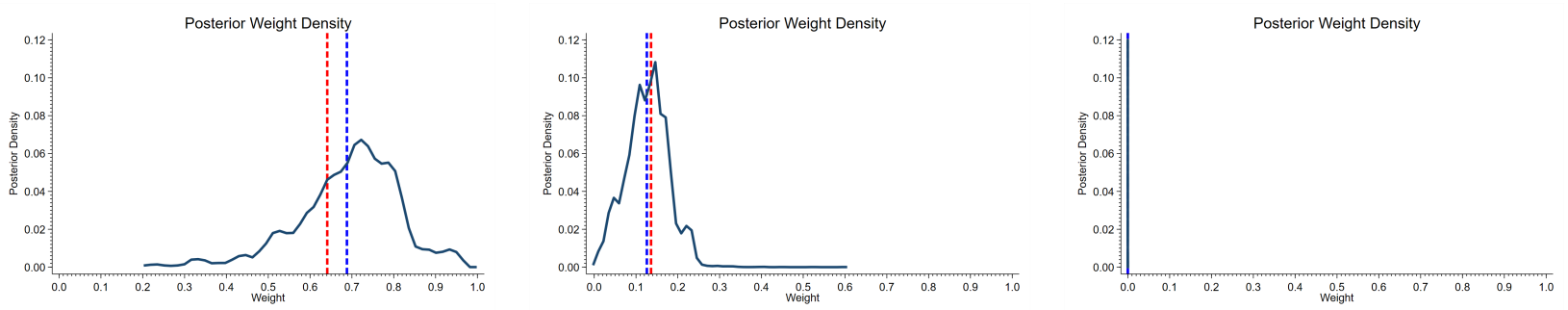
Figure 4: Bayesian Inference - Unemployment

(a) Counterfactuals and Probability Intervals

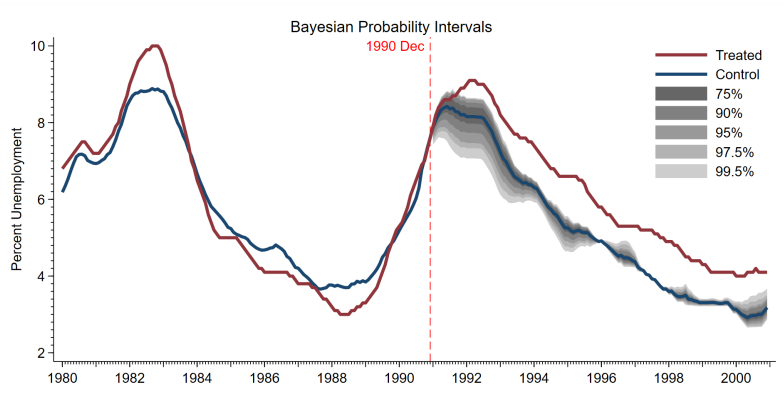

(b) Probability Interval for Average Treatment Effect

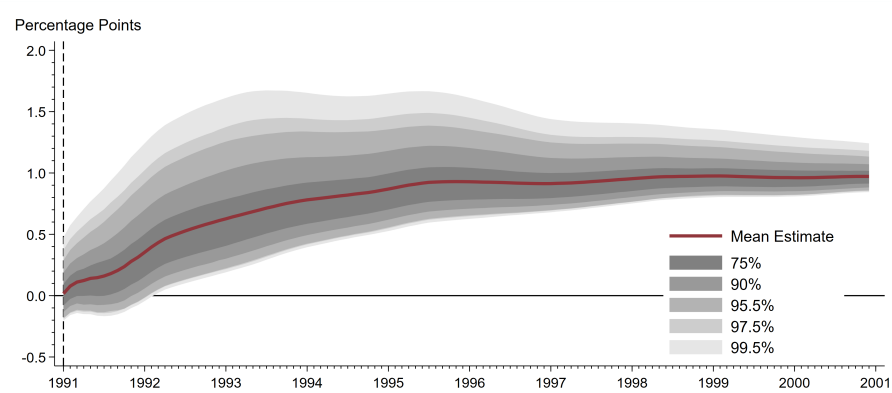

Figure 5: Bayesian Inference - Labor Force Participation Ratio

(a) Counterfactuals and Probability Intervals

(b) Probability Interval for Average Treatment Effect
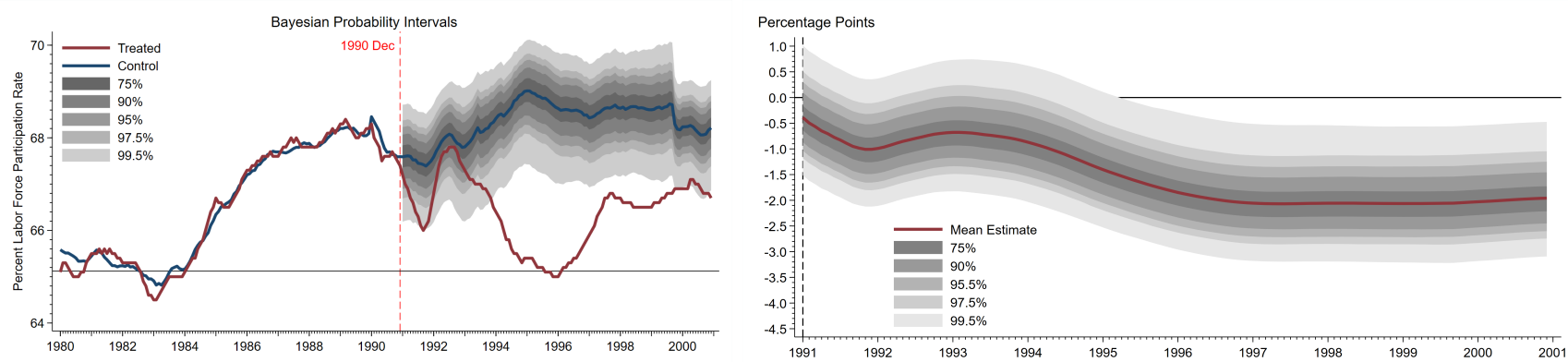

Figure 6: Bayesian Inference - Gross State Product

(a) Counterfactuals and Probability Intervals

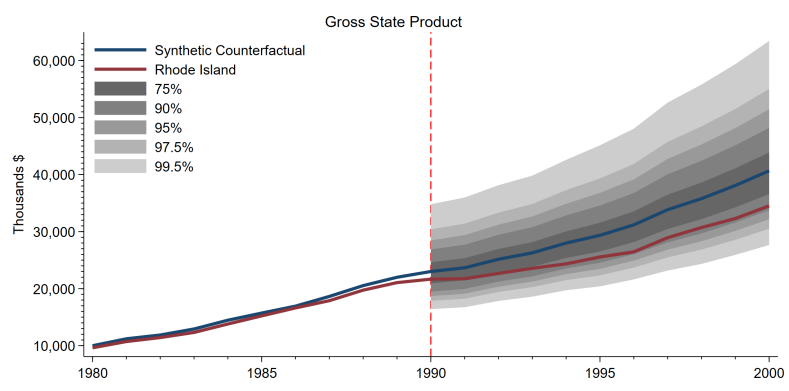

(b) Probability Interval for Average Treatment Effect

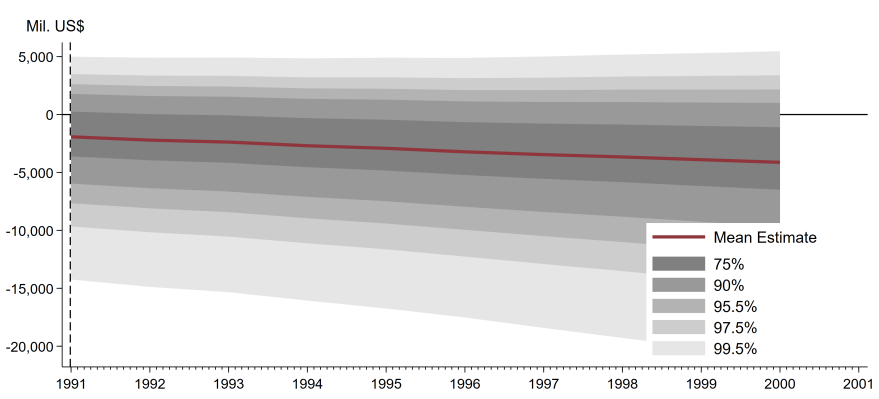



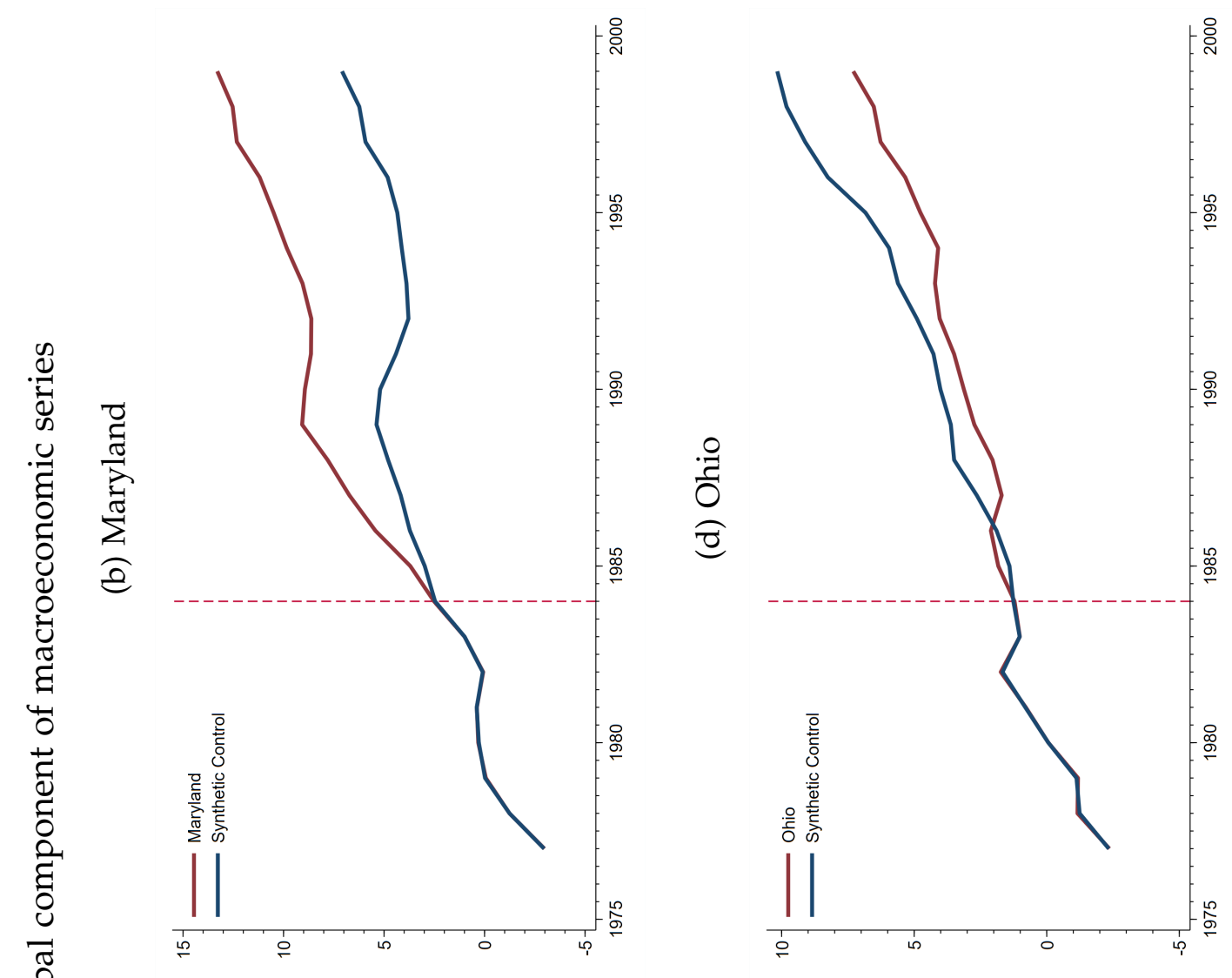

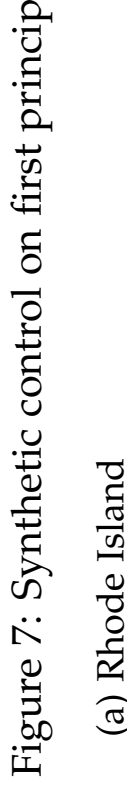

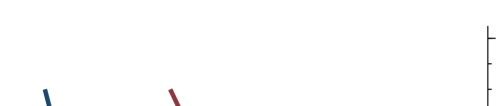

옹

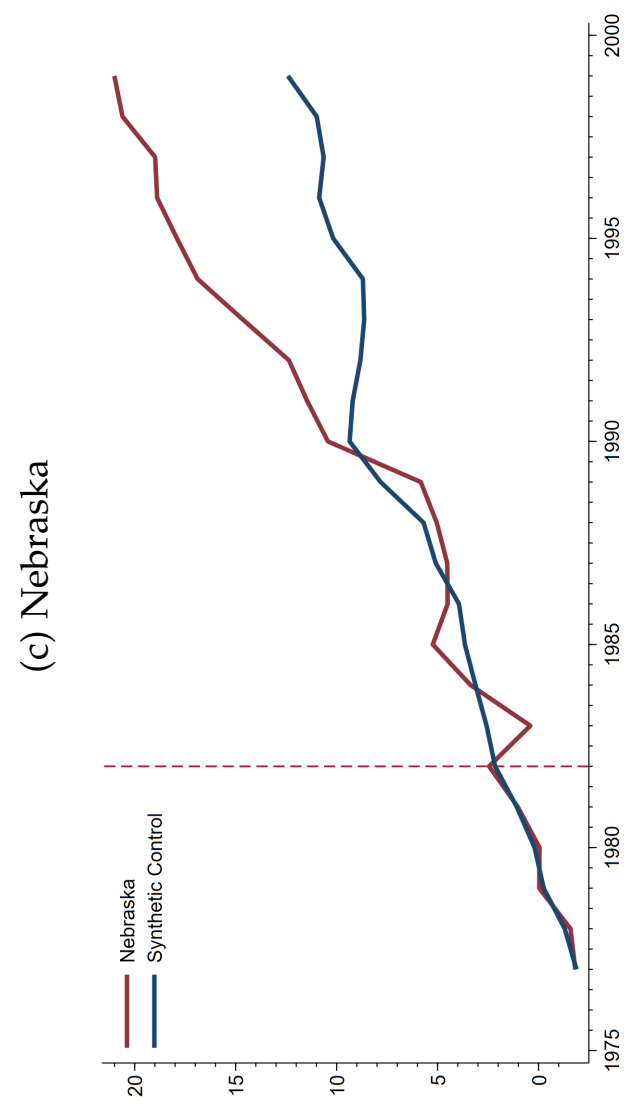


Figure 8: Different Business Cycles

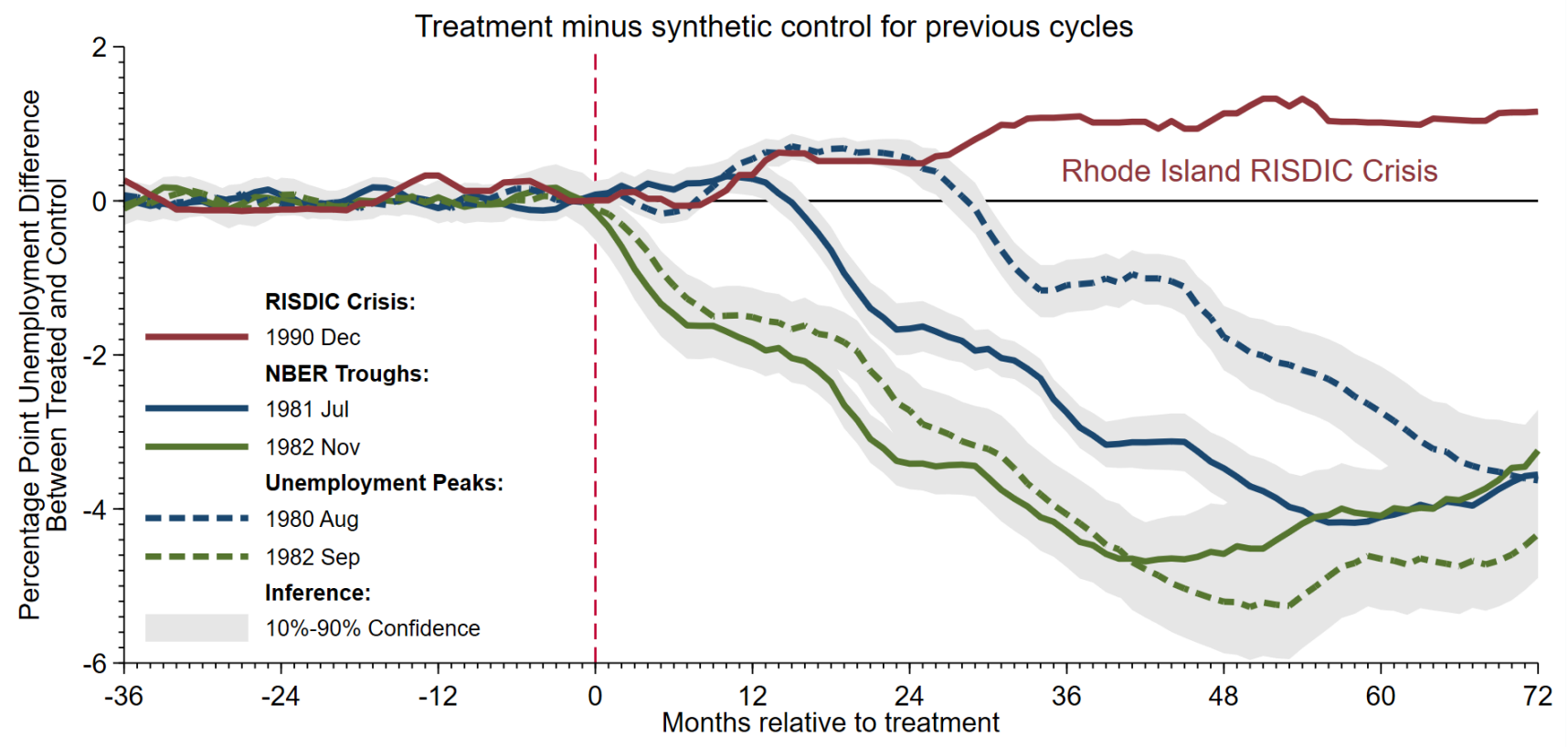

Figure 9: Robustness - 3 Year Pre-Treatment

(a) Counterfactuals 3 Year Pre-Treatment Match

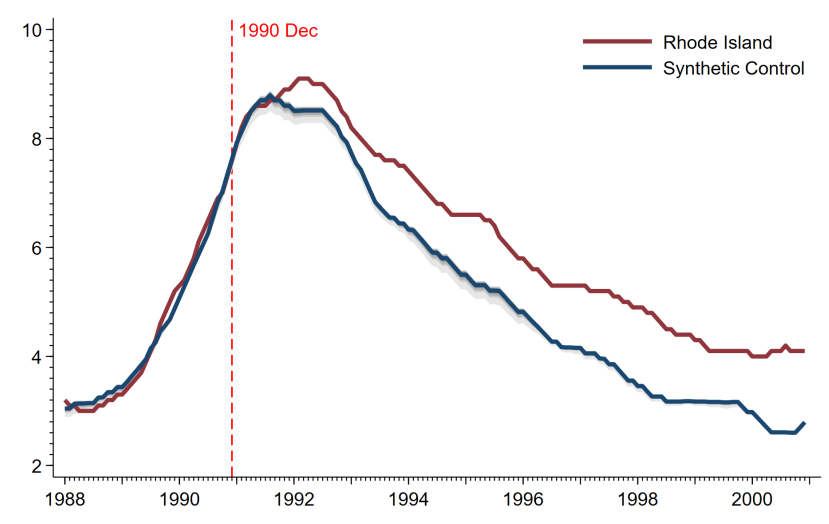

(b) Difference Treatment-Counterfactual

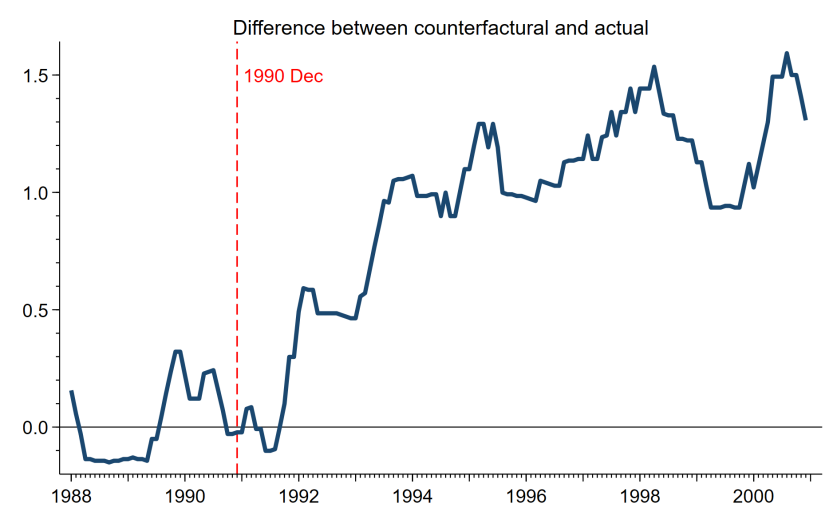


Figure 10: County-level Border Comparison

(a) Establishments

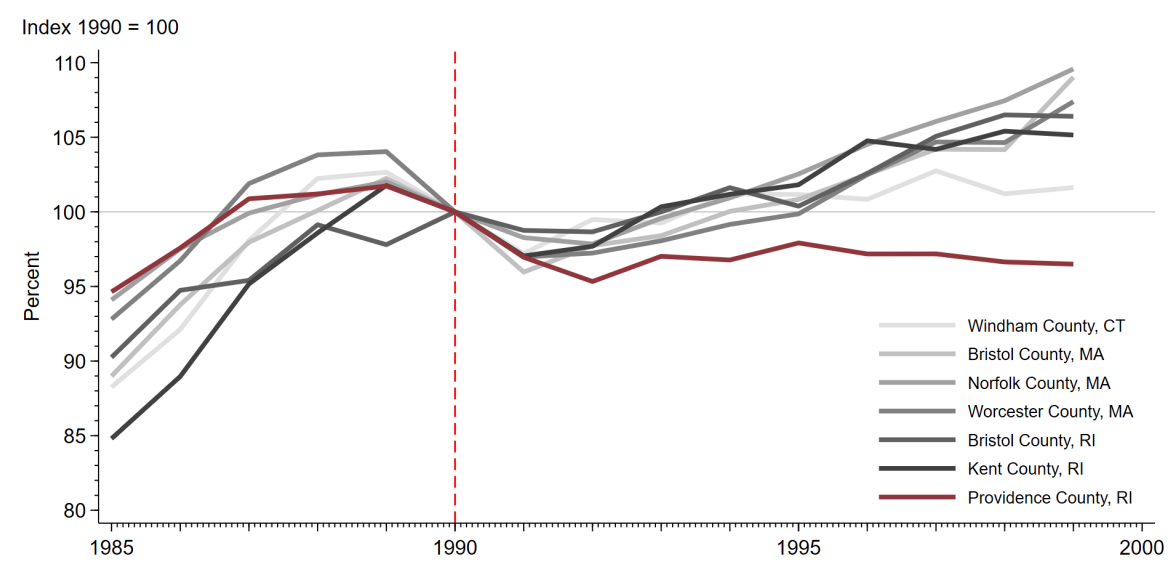

(b) Employment

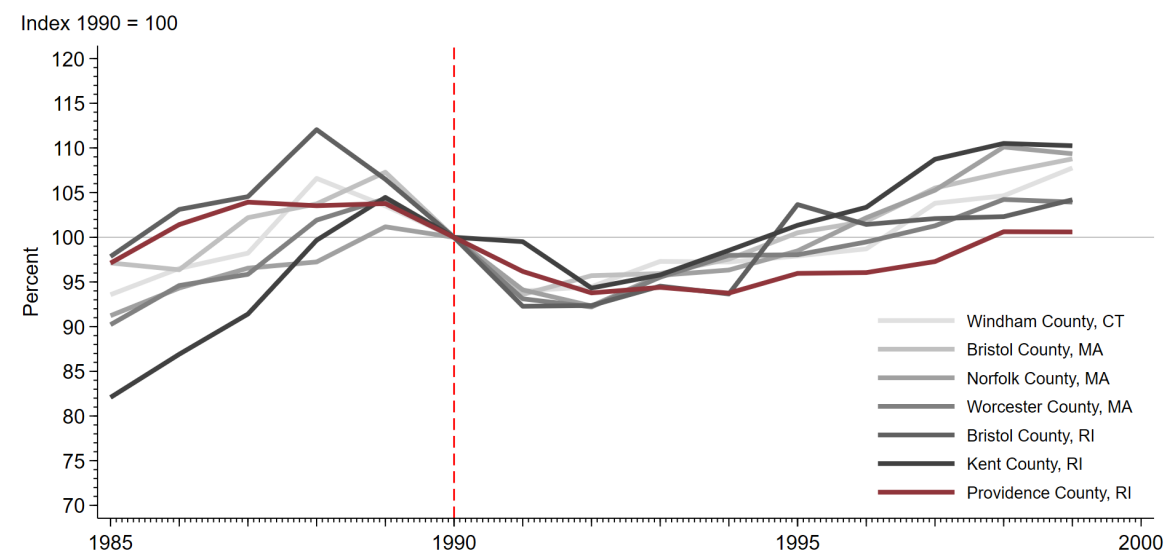

Figure 11: County-level Synthetic Control Results

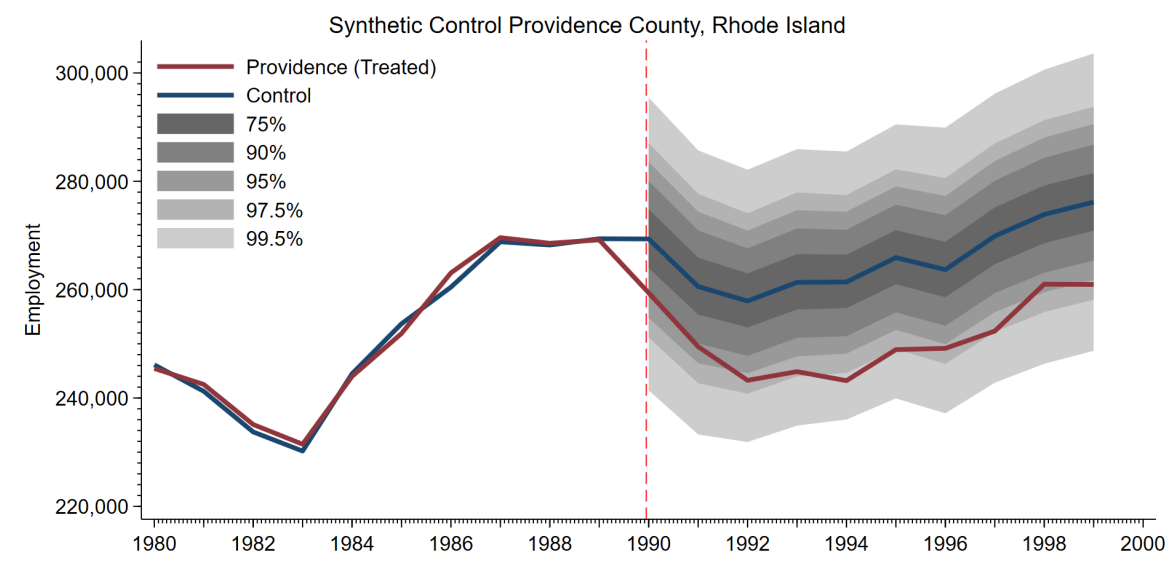




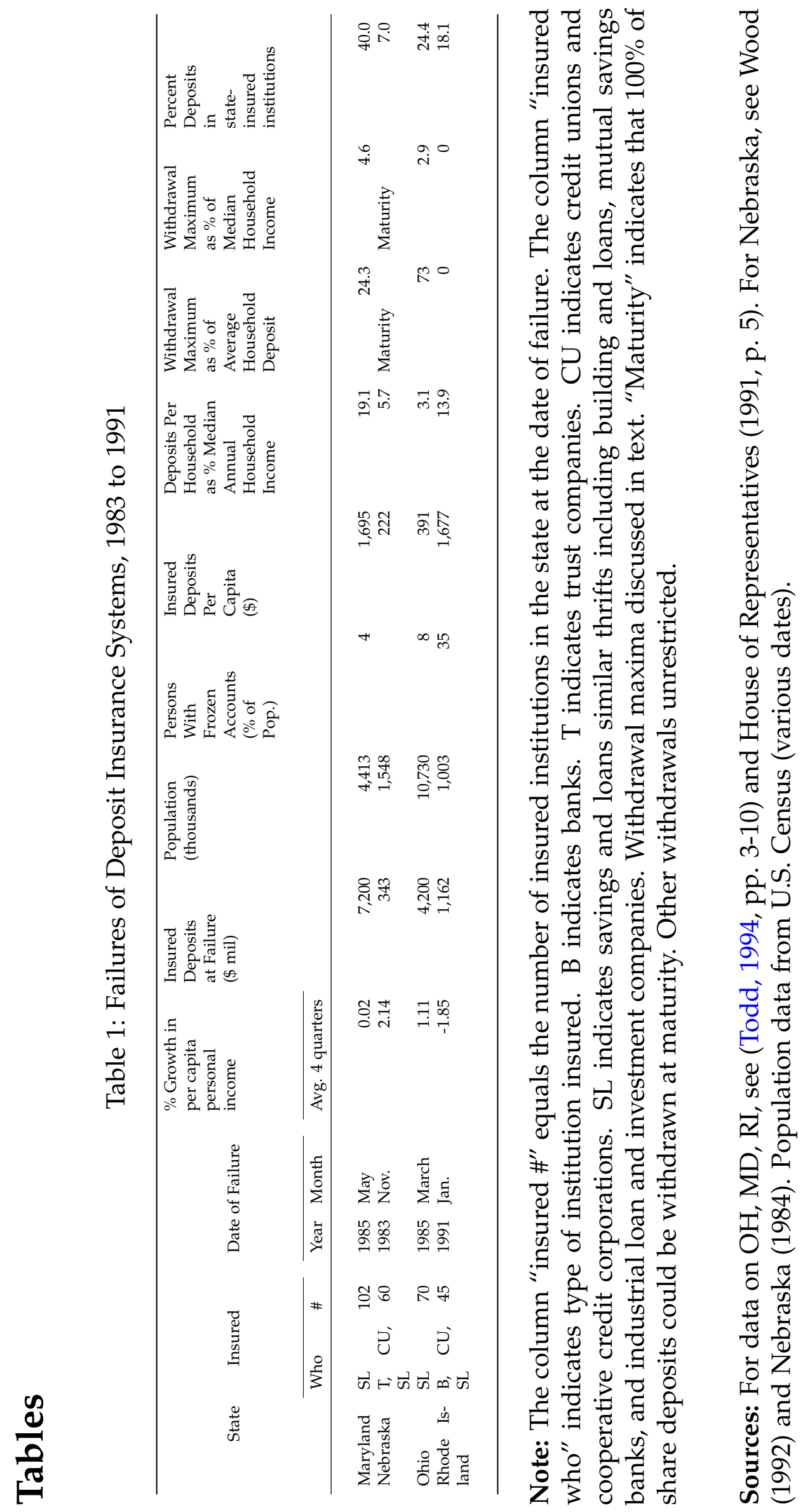




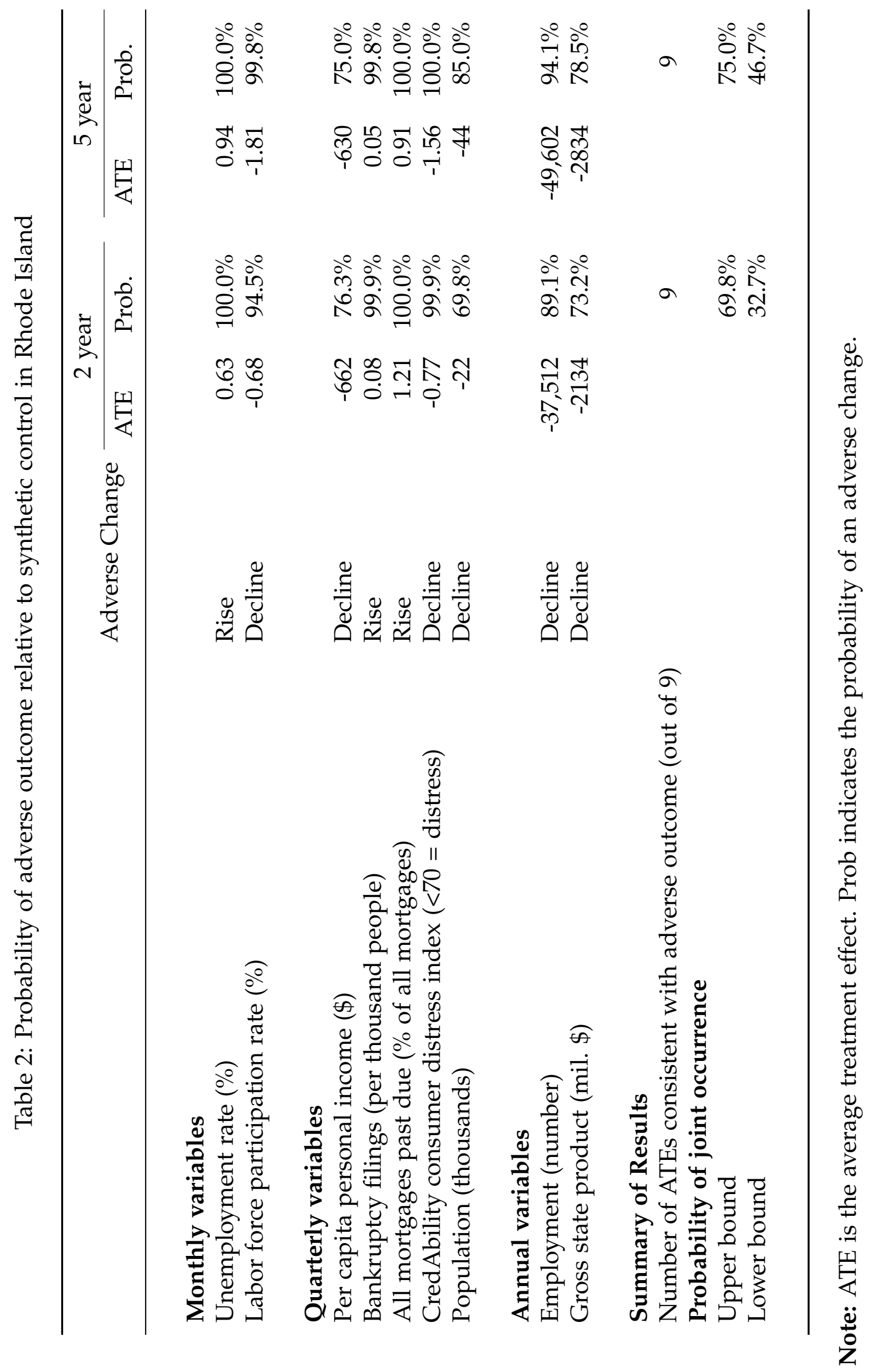




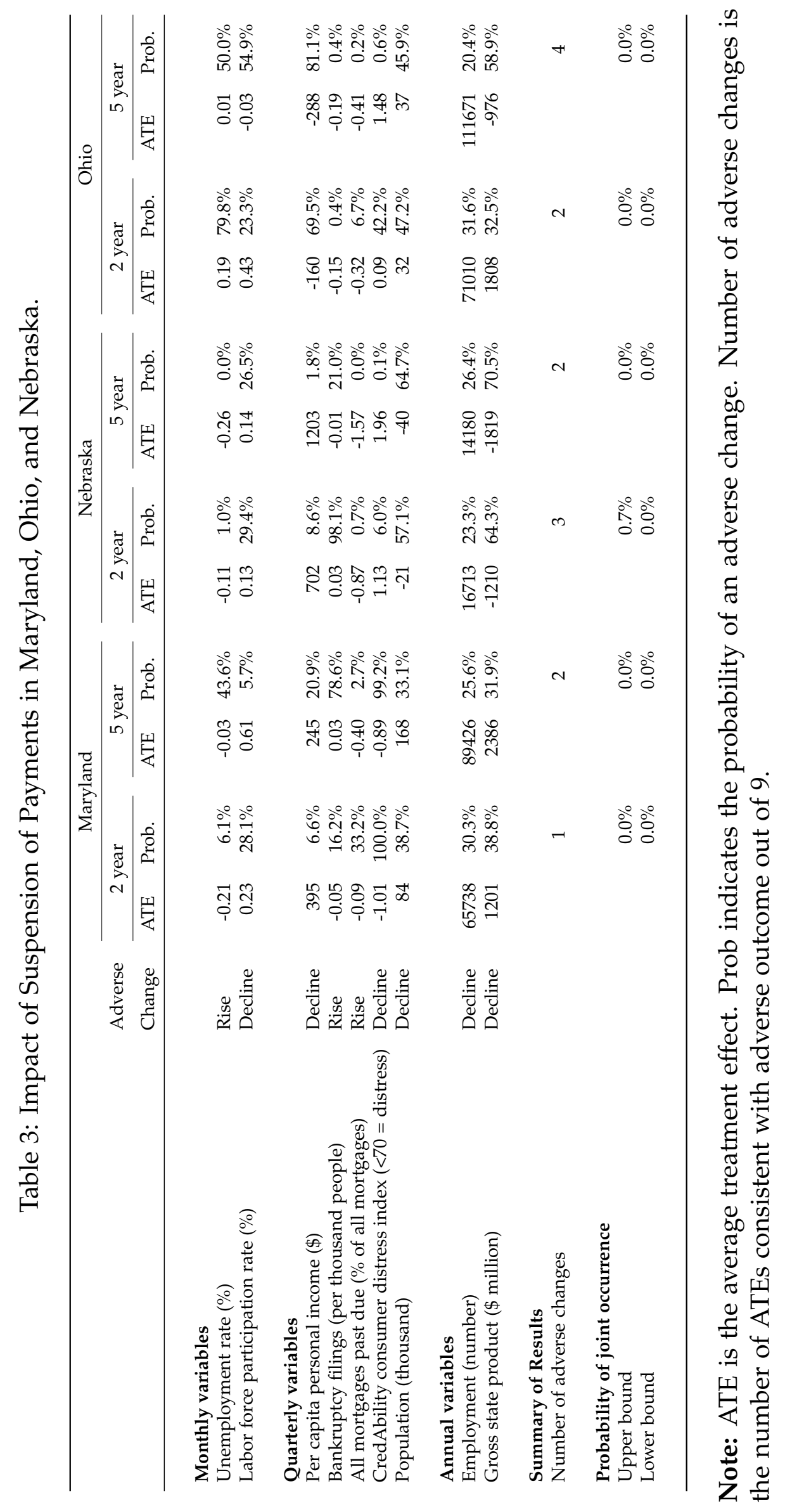


Table 4: Payments Crises and Sectoral GDP

\begin{tabular}{|c|c|c|c|c|c|c|c|c|}
\hline \multirow[b]{2}{*}{ Components of GDP (\$ millions) } & \multicolumn{2}{|c|}{ Rhode Island } & \multicolumn{2}{|c|}{ Maryland } & \multicolumn{2}{|c|}{ Nebraska } & \multicolumn{2}{|c|}{ Ohio } \\
\hline & ATE & Prob. & ATE & Prob. & ATE & Prob. & ATE & Prob. \\
\hline \multicolumn{9}{|l|}{ Cyclical } \\
\hline FIRE & -297 & $91.8 \%$ & 681 & $29.9 \%$ & -454 & $81.1 \%$ & -1154 & $81.5 \%$ \\
\hline Services & -353 & $86.6 \%$ & 1127 & $14.4 \%$ & -25 & $56.8 \%$ & -729 & $54.6 \%$ \\
\hline Manufacturing & -4686 & $100.0 \%$ & -365 & $54.1 \%$ & -198 & $64.0 \%$ & 3209 & $1.8 \%$ \\
\hline Retail Trade & -225 & $96.5 \%$ & 487 & $20.8 \%$ & -78 & $64.6 \%$ & -178 & $76.5 \%$ \\
\hline Wholesale Trade & -262 & $99.9 \%$ & -160 & $62.7 \%$ & -487 & $81.8 \%$ & -171 & $52.0 \%$ \\
\hline Construction & 112 & $5.0 \%$ & 623 & $15.7 \%$ & -52 & $90.6 \%$ & -496 & $77.6 \%$ \\
\hline \multicolumn{9}{|l|}{ Acyclical } \\
\hline Transport/Communication/Public Utilities & 156 & $1.7 \%$ & 177 & $23.3 \%$ & -303 & $81.0 \%$ & -945 & $90.2 \%$ \\
\hline Agriculture, Forestry, Fisheries & -14 & $62.9 \%$ & 147 & $0.4 \%$ & 170 & $17.7 \%$ & 11 & $41.1 \%$ \\
\hline \multicolumn{9}{|c|}{ Probability of joint occurrence of cyclical components excluding construction } \\
\hline Upper bound & & $86.6 \%$ & & $14.4 \%$ & & $56.8 \%$ & & $1.8 \%$ \\
\hline Lower bound & & $76.6 \%$ & & $0.3 \%$ & & $15.6 \%$ & & $0.3 \%$ \\
\hline
\end{tabular}

Note: ATE is average treatment effect after 5 years. Prob is probability of an adverse change.

Table 5: Bank Credit in New England: 1990 and 1991

\begin{tabular}{|c|c|c|c|c|c|c|c|c|}
\hline & \multirow{2}{*}{\multicolumn{2}{|c|}{ Total }} & \multicolumn{6}{|c|}{ Type of Lending } \\
\hline & & & \multicolumn{2}{|c|}{ Real Estate } & \multicolumn{2}{|c|}{$C \& I$} & \multicolumn{2}{|c|}{ Consumer } \\
\hline & 1990 & 1991 & 1990 & 1991 & 1990 & 1991 & 1990 & 1991 \\
\hline Rhode Island & -7.07 & 0.72 & -8.05 & 20.45 & 6.13 & -14.77 & -19.63 & -26.30 \\
\hline Connecticut & -10.54 & -13.20 & -7.38 & -8.18 & -16.30 & -29.43 & -22.76 & -23.61 \\
\hline Maine & -5.62 & -7.49 & -5.07 & -5.03 & -5.05 & -21.80 & -8.65 & -1.97 \\
\hline Massachusetts & -13.22 & -13.33 & -9.93 & -11.03 & -16.33 & -14.73 & -23.01 & -18.52 \\
\hline New Hampshire & -11.46 & -11.08 & -7.41 & -11.37 & -20.51 & -25.82 & -16.44 & -0.82 \\
\hline Vermont & -0.13 & -4.07 & 4.53 & -0.38 & -14.60 & -10.83 & -2.48 & -14.99 \\
\hline
\end{tabular}

Note: Year-over-year percent growth for lending in each category on December 31 of each year.

Source: Call reports of federally insured financial institutions from https://www . chicagofed. org/banking/financial-institution-reports/commercial-bank-data 


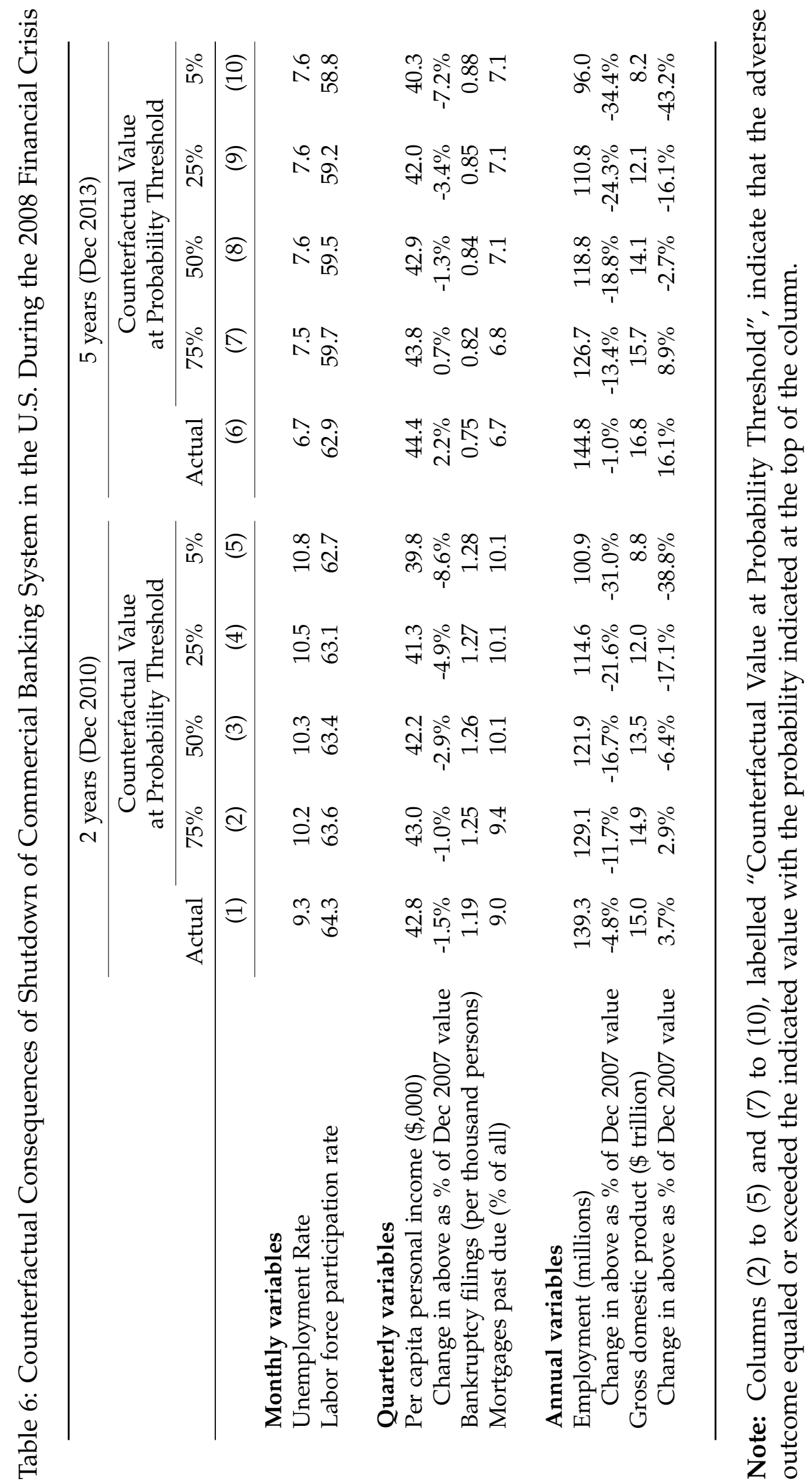




\section{Appendix}

Our paper contains two appendices intended for online distribution. Appendix A describes the data that we analyze. Appendix B provides additional historical background.

\section{A Data}

For online distribution only.

The subsequent variable source table displays the data mnemonics, data description, and data source for the time-series used in this paper.

Table: Variable Sources and Data Mnemonics

\begin{tabular}{|c|c|c|}
\hline Haver Mnemonic & Description & Source \\
\hline \multicolumn{3}{|c|}{ U.S. National Level Data } \\
\hline LR@USECON & Unemployment Rate (SA, \%) & Bureau of Labor Statistics \\
\hline LP@USECON & Labor Force Participation Rate (SA, \%) & Bureau of Labor Statistics \\
\hline ES0TZ0@CEW & Establishments (Number) & Bureau of Labor Statistics \\
\hline USL14@MBAMTG & All Mortgages Past Due (NSA, \%) & Mortgage Bankers Association \\
\hline USABQ@BANKRUPT & Bankruptcy Filings, U.S. (Units) & Administrative Office of the U.S. Courts \\
\hline USBBQ@BANKRUPT & Business Bankruptcy Filings, U.S. (Units) & Administrative Office of the U.S. Courts \\
\hline USNBQ@BANKRUPT & Nonbusiness Bankruptcy Filings, U.S. (Units) & Administrative Office of the U.S. Courts \\
\hline USTO@GSP & Gross Domestic Product & Bureau of Economic Analysis \\
\hline \multicolumn{3}{|c|}{ U.S. State Level Data } \\
\hline ??LA@EMPLR & Unemployment Rate (SA, \%) & Bureau of Labor Statistics \\
\hline ??RA@EMPLR & Labor Force Participation Rate (SA, \%) & Bureau of Labor Statistics \\
\hline ??YPPQ@PIQR & Per capita personal income $(\$)$ & Bureau of Economic Analysis \\
\hline ??L14@MBAMTG & All mortgages past due $(\%)$ & Mortgage Bankers Association \\
\hline ??ABPQ@BANKRUPT & Bankruptcy filings per capita (per thous people) & Administrative Office of the U.S. Courts \\
\hline ??BBPQ@BANKRUPT & Business bankruptcy filings per capita (per thous people) & Administrative Office of the U.S. Courts \\
\hline ??NBPQ@BANKRUPT & Nonbusiness bankruptcy filings per capita (per thous people) & Administrative Office of the U.S. Courts \\
\hline ??POPQ@PIQR & Population (thous) & Bureau of Economic Analysis \\
\hline ??L14@MBAMTG & All Mortgages Past Due (NSA, \%) & Mortgage Bankers Association \\
\hline ??CDI@REGIONAL & CredAbility Consumer Distress Index & CredAbility \\
\hline ??@CEWR & Employment & Bureau of Labor Statistics \\
\hline ??TSZ0@CEWR & Establishments & Bureau of Labor Statistics \\
\hline ??TO@GSP & Gross State Product & Bureau of Economic Analysis \\
\hline \multicolumn{3}{|c|}{ U.S. County Level Data } \\
\hline ??!!!S0@CEWC & Establishments & United States Census Bureau \\
\hline ??!!!E0@CEWC & Employment & United States Census Bureau \\
\hline
\end{tabular}

Notes: In the table, in the state and county level panels ?? stands in for the two letter U.S. state post code, i.e. AL AK AZ AR CA CO CT DC DE FL GA HI ID IL IN IA KS KY LA ME MD MA MI MN MS MO MT NE NV NH NJ NM NY NC ND OH OK OR PA RI SC SD TN TX UT VT VA WA WV WI WY. In the county level panel !!! stands in for three letter county abbreviations. Note that the county level data is downloaded from Inter-university Consortium for Political and Social Research (ICPSR) as Haver Analytics carries only recent data. 


\section{B History of the Four State Insurance Systems}

For online distribution only.

In Nebraska, the Nebraska Depository Institution Guaranty Corporation (NDIGC) was chartered in 1976 and began operations two years later (Wood 1992). It insured deposits at state-chartered industrial savings companies and cooperative credit corporations. The insurance fund and its members were supervised by the Nebraska Department of Banking and Finance. On December 31, 1983, NDIGC insured 33 industrial loan and investment companies (including savings banks) with $\$ 309$ million in deposits, 24 cooperative credit associations with $\$ 32$ million in deposits, two credit unions with $\$ 1$ million in deposits, and one trust company with $\$ 2$ million in deposits. In total, NDICG insured 60 institutions with $\$ 343$ million in deposits (Nebraska 1984, pp. 148-58).

On November 1, 1983, the department closed the NDIGC's largest member, the Commonwealth Savings Company. The action triggered runs at other NDICG-insured institutions. In response, the department publicly ordered all industrial loan and investment companies to refuse to allow depositors to withdraw funds until the depositors' certificates of indebtedness had matured. Depositors could continue to access funds in checking accounts (English 1993, p. 67; Wood 1992). When the investment certificates came due, the fund's second- and thirdlargest industrial savings companies also failed, in July 1984 and January 1985, respectively. All other NDIGC members switched to federal deposit insurance, by taking out bank or credit union charters and joining the FDIC or NCUA respectively.

Ohio established the Ohio Deposit Guaranty Fund (ODGF) to insure state-chartered S\&Ls in 1956. Ohio's Building and Loan Commissioner supervised the OGDF and its members. At the beginning of 1985, OGDF insured 70 institutions with $\$ 4,200$ million in total deposits. ${ }^{12}$

In March 1985, OGDF's largest member was Home State, which accounted for 19\% of the total deposits insured by the fund. Home State had borrowed $\$ 535$ million from ESM Government Securities, a Florida securities dealer, using repurchase agreements which required Home State to provide collateral worth $\$ 680$ million. "When ESM failed [on March 4], Home State lost \$145 million due to the 'overcollateralization' of its loan. This loss was slightly larger than the sum of Home State's net worth and the value of the assets of the ODGF (English 1993, p. 69)." Runs on Home State began immediately. In four days, depositors withdrew \$150 million. On Saturday March 9, Home State did not open, and Ohio appointed a conservator. The next week, runs began on other ODGF-insured institutions. Ohio tried to stem the runs by announcing the establishment of a new insurance fund to insure S\&Ls other than Home State, but the runs continued, and on Friday March 15, Ohio's Governor announced

\footnotetext{
${ }^{12}$ At that time, credit unions in Ohio were insured by a different corporation, the National Deposit Guarantee Corporation (NDGC), which was chartered by Ohio in 1974, expanded across state lines to ensure credit unions in three states $(\mathrm{OH}, \mathrm{IL}, \mathrm{WV})$ by the early 1980s, and which continues to operate today as American Share Insurance.
} 
a banking holiday and closed all OGDF institutions. Five days later, the state passed a law requiring all state-chartered S\&Ls to apply for federal insurance and allowed those deemed likely to get FSLIC insurance to reopen. Others were allowed to reopen, permitting customers to withdraw up to $\$ 750$ per month (Todd, 1994). To expedite the reopenings, "about 160 bank examiners from the Federal Reserve System help[ed] those from the FSLIC and the Federal Home Loan System evaluate ODGF members" and Ohio's legislature provided \$125 million to cover ODGF losses (English 1993, p. 116)." Ultimately, 35 of 70 ODGF institutions obtained FSLIC insurance, 10 obtained FDIC insurance, 24 (including Home State) merged with or were acquired by health institutions with federal insurance (either FSLIC or FDIC), and 1 liquidated (English, 1993, p. 68-70).

In 1962, Maryland established the Maryland Savings Share Insurance Corporation (MSSIC) in 1962. MSSIC insured deposits at stated-chartered S\&Ls. The Maryland Division of Savings and Loans supervised MSSIC and its members. At the beginning of 1985, MSSIC insured 102 institutions with deposits totaling $\$ 7,200$ million. $^{13}$

Maryland's S\&Ls experienced increasing difficulties in the spring of 1985. Problems arose in part because of widespread discussion of problems faced by the S\&L industry and in part because of the failure of ODGF in Ohio. This bad news impeded S\&L's efforts to attract deposits and triggered declines in deposits at many institutions. Problems also arose because of inadvisable or illegal activity at several S\&Ls. On Friday May 9, an article in the Baltimore Sun reported regulatory violations and risky investments at and triggered rapid runs on Old Court S\&L, the second largest member of the MSSIC, and another Merritt Commercial S\&L. On Tuesday May 13, Old Court entered conservatorship, as did Merritt one day later. On Wednesday May 14, Maryland's governor imposed a \$1,000-a-month limit on withdrawals from MSSIC institutions (later amended to permit payments of mortgages, payrolls, and similar needs). On May 18, the state established a new corporation, the Maryland Deposit Insurance Fund (MDIF) and endowed it with $\$ 100$ million to protect depositors while MSSIC institutions applied for FSLIC membership. The state required all S\&Ls to join the FSLIC within four years. By mid July, 60 thrifts were operating without constraints under MDIF insurance. 14 were operating without constraint under FSLIC insurance. 26 MSSIC institutions still operated under the restricted withdrawal regime. Two institutions were in liquidation (Old Court and First Maryland). A third S\&L, Community, entered liquidation in August. Depositors at all three eventually received their deposits in full in quarterly installments through 1989 (without accruing interest after the institutions entered receivership).

Rhode Island established the Rhode Island Share and Deposit Indemnity Corporation (RSDIC), a state-chartered privately-operated insurance fund in 1969. RSDIC insured deposits at stated-chartered savings banks, loan and investment companies, and credit unions. Rhode Island's banking superintendent insured RSDIC and its members. In December 1990, RSDIC

\footnotetext{
${ }^{13}$ Like Ohio, Maryland established a separate insurance fund for state-chartered credit unions, the Maryland Credit Union Insurance Corporation. In late 1983, it insured 27 credit unions with deposits totaling \$439 million.
} 
insured 45 financial institutions with over 357,000 individual accounts. This amounted to one account for every three of Rhode Island's one-million residents, forty-six accounts for every one-hundred Rhode Island residents over the age of 18 , or roughly one account per household in the state (U.S. Bureau of the Census, 1993)

In 1990, RISDIC's members found themselves under pressure from the business cycle downturn which was particularly severe in New England at that time (Pulkkinen and Rosengren, 1993; Todd, 1994). Real estate loan and investment losses accumulated at many institutions. Two RISDIC members encountered severe problems. In February, regulators revealed that Jefferson Loan and Investment Bank borrowed its capital from another financial institution in violation of state regulations, recorded equipment lease income improperly, and paid exorbitant management fees to its parent holding company. RISDIC took control of Jefferson and reserved \$3.9 million to cover Jefferson's losses.

In the fall of 1990, regulators discovered defalcations so large that they threatened the solvency of Heritage Loan and Investment Company. Heritage had loaned \$13 million of its $\$ 25$ million in assets to 128 individuals and organizations who neither applied for nor received the funds, which instead went in to the pocket of the bank's president, Joseph Mollicone Jr., who was also on RISDIC's board of directors. News of the illegitimate loans induced substantial withdrawals from Heritage. In October and November, RISDIC injected \$17.5 million into Heritage and assessed other RISDIC members $\$ 5.5$ million to maintain RISDIC's reserve level. On November 8, 1990, Joseph Mollicone disappeared. ${ }^{14}$ News of his disappearance triggered a run on Heritage. On November 16, after the withdrawal of most of its deposits (which were paid with funds from RISDIC), Heritage closed. Runs on other institutions accelerated. The Rhode Island Central Credit Union, which had assets over \$270 million, was particularly hard hit. To cover withdrawals in the first two weeks of December, it borrowed \$20 million from the Rhode Island Credit Union League-Corporate Central Union (RICUL-CCU). At the end of the month, RICUL-CCU refused to extend additional credit to Rhode Island Central, and to secure outstanding loans, took over Rhode Island Central's assets and premises (Todd, 1994). RISDIC was unable to help. Its funds were depleted and reputation tarnished. On December 31, its board decided against a second assessment of members and asked the state to appoint a conservator to resolve its affairs. The announcement seemed certain to accelerate the runs on financial institutions underway throughout the state.

So, on January 1, 1991, a few hours after taking office, Rhode Island's governor froze all accounts in RISDIC insured institutions (Pulkkinen and Rosengren, 1993; Todd, 1994, p. 10). About two-thirds of all RISDIC-insured deposits were frozen for the greater part of the year. The full amount of deposits at five RISDIC-insured institutions was not returned for nearly 3 years.

Rhode Island replaced RISDIC with a new organization, the Depositors Economic Pro-

\footnotetext{
${ }^{14}$ Two years later, he was arrested, tried, convicted, and imprisoned.
} 
tection Corporation (DEPCO). The state issued $\$ 150$ million to assist in providing 100 percent coverage for all deposits up to $\$ 100,000$ and partial insurance for deposits over that amount in the 14 closed institutions. The bonds were to be repaid from liquidating the failed institutions' assets and from a 0.5 percent increase in the state sales tax. On February 9, 1991, the governor of Rhode Island promised that payments to depositors would be made within 60 days, but by January of 1992, depositors had received only about 10 percent of their deposits. Nine institutions remained closed despite state efforts to sell them. By June 1992, 18 months after the closings, all but 38,000 depositors had received their deposits and those depositors had received 90 percent of their money. Costs to the state of Rhode Island reached $\$ 471$ million as of June 1992. 